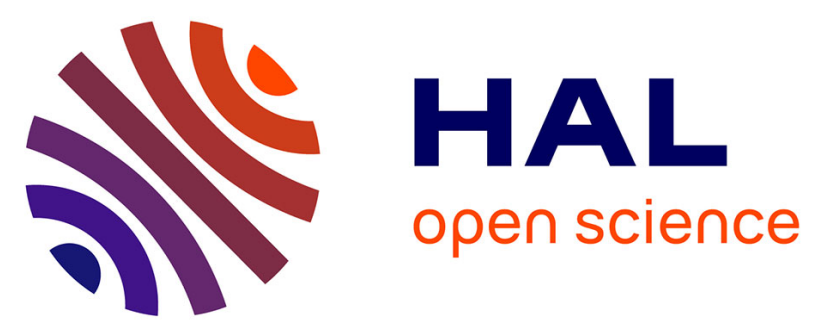

\title{
Varying the spatial arrangement of synthetic herbivore-induced plant volatiles and companion plants to improve conservation biological control
}

Coline C Jaworski, Da Xiao, Qingxuan Xu, Ricardo Ramirez-Romero, Xiaojun Guo, Su Wang, Nicolas Desneux

\section{To cite this version:}

Coline C Jaworski, Da Xiao, Qingxuan Xu, Ricardo Ramirez-Romero, Xiaojun Guo, et al.. Varying the spatial arrangement of synthetic herbivore-induced plant volatiles and companion plants to improve conservation biological control. Journal of Applied Ecology, 2019, 56 (5), pp.1176-1188. 10.1111/13652664.13353 . hal-02107739

\section{HAL Id: hal-02107739 \\ https://hal.science/hal-02107739}

Submitted on 23 Apr 2019

HAL is a multi-disciplinary open access archive for the deposit and dissemination of scientific research documents, whether they are published or not. The documents may come from teaching and research institutions in France or abroad, or from public or private research centers.
L'archive ouverte pluridisciplinaire HAL, est destinée au dépôt et à la diffusion de documents scientifiques de niveau recherche, publiés ou non, émanant des établissements d'enseignement et de recherche français ou étrangers, des laboratoires publics ou privés. 


\title{
Varying the spatial arrangement of synthetic herbivore-induced plant volatiles and companion plants to improve conservation biological control
}

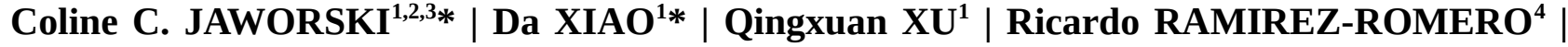 \\ Xiaojun GUO $^{1}$ | Su WANG ${ }^{1}$ | Nicolas DESNEUX ${ }^{5}$
}

\author{
${ }^{1}$ Beijing Key Laboratory of Environment \\ Friendly Management on Fruit Disease and \\ Pests in North China, Institute of Plant \& \\ Environment Protection, Beijing Academy \\ of Agricultural and Forestry Sciences \\ ${ }^{2}$ Aix-Marseille University, Mediterranean \\ Institute of Marine and Terrestrial \\ Biodiversity and Ecology, UMR 7263 \\ CNRS, IRD, Avignon University, Marseille, \\ France. \\ ${ }^{3}$ Department of Zoology, University of \\ Oxford, Oxford, OX1 3PS, U.K. \\ ${ }^{4}$ Biological Control Laboratory, \\ Department of Agricultural Production, \\ CUCBA, University of Guadalajara, \\ Zapopan, Jalisco, Mexico \\ ${ }^{5}$ INRA (French National Institute for \\ Agricultural Research), University Côte \\ d'Azur, CNRS, UMR 1355-7254, Institut \\ Sophia Agrobiotech, Sophia Antipolis, \\ France
}

* These authors contributed equally to this work.

\section{Correspondence}

Su Wang,

Email: anthocoridae@163.com and Nicolas Desneux

Email: nicolas.desneux@inra.fr

\begin{abstract}
1. Conservation biological control aims to control pests by promoting wild populations of natural enemies. One challenge is to attract and retain efficient natural enemies in crop fields, which often are a suboptimal environment. Towards this goal, the attract-and-reward strategy relies on combining attractive synthetically produced herbivore-induced plant volatiles (HIPVs) with companion plants (non-crop plants which provide alternative resources to the targeted natural enemies). Although severely overlooked, the spatial arrangement of HIPV dispensers and rewards inside crop fields may strongly influence the foraging behaviour and persistence of natural enemies and thus the success of this pest management strategy.

2. We tested the impact of two contrasting spatial arrangements of HIPV dispensers and rewards, alternatively inside and around a block of target apple trees, on the efficacy of the biological control of Aphis citricola populations by the common predatory ladybird Propylea japonica in apple orchards in northern China. We used synthetic methyl salicylate (MeSA) as an attractant and the companion plant Calendula officinalis as a reward. To better understand how the spatial arrangement of MeSA dispensers and companion plants affected the attraction and foraging behaviour of adult ladybirds, we conducted indoor experiments in a flight mill, an olfactometer and a wind-tunnel.

3. Blocks of target trees treated with MeSA dispensers inside and companion plants around provided the most efficient pest control in orchards, compared with the opposite spatial arrangement.

4. The synthetic MeSA dispenser and the companion plant synergistically attracted ladybirds in the olfactometer and enhanced their flight activity in the flight mill. In the wind-tunnel, MeSA served as a spatial cue for ladybirds to find nearby prey, while companion plants were sought in the absence of prey.

5. Synthesis and applications. The present study will help further improvements of aphid control in apple orchards through a careful spatial arrangement of herbivore-induced plant volatiles dispensers (HIPVs) and rewards (companion plants) in optimized attract-and-reward strategies. Without such assessment, these strategies may be hazardous even with wellidentified targeted natural enemies. Associated lab experiments highlight that HIPVs and companion plants interactively influence ladybird foraging pattern, and that their spatial arrangement can modulate the ability of such key predators to find their prey.
\end{abstract}

\section{KEYWORDS}

attract-and-reward, foraging behaviour, integrated pest management, methyl salicylate, natural enemies, semiochemicals,synomone

How to cite this article: Jaworski CC, Xiao D, Xu Q, et al.

Varying the spatial arrangement of synthetic herbivore-induced plant volatiles and companion plants to improve conservation biological control. J Appl Ecol. 2019;00:1-13.

https://doi.org/10.1111/1365-2664.13353 


\section{1 | INTRODUCTION}

Conservation biological control (CBC) has drawn increasing attention in recent decades, along with important development and implementation (Tschumi et al., 2016; Gurr et al., 2017; Michaud, 2018). It relies on environmental manipulation to preserve pests' natural enemies and promote their effectiveness (Fiedler et al., 2008; Gurr et al., 2017). This approach thus avoids the detrimental side effects associated with classical augmentative biological control programs, such as the overgrowth of introduced natural enemies (Simberloff \& Stiling, 1996; Louda et al., 2003).

A promising method in CBC is the attract-andreward strategy, in which the colonization of crop fields by natural enemies is enhanced via attraction from surrounding habitats and their persistence and population growth is enhanced via the reward (Simpson et al., 2011a). The attractants are synthetically-produced molecules similar to natural herbivore-induced plant volatiles (HIPVs), such as methyl salicylate (MeSA) and methyl jasmonate. Plants naturally emit large amounts of HIPVs in response to herbivorous attacks, and these chemicals are long-distance attractants of herbivorous arthropods' natural enemies (Turlings \& Erb, 2018). The effect of synthetic MeSA is comparable to that of naturally emitted MeSA, and it has been widely implemented in CBC targeting natural enemies such as hemipteran bugs, coccinellids and hoverflies (Zhu \& Park, 2005; Rodriguez-Saona et al., 2011; Gadino et al., 2012). In particular, the MeSA plant-defence pathway is induced by phloem-sucking insects such as aphids, while the methyl jasmonate pathway is induced by leaf chewers (Soler et al., 2012). Therefore MeSA is likely more relevant to coccinellids, which essentially depend on aphids as a food resource (Vandereycken et al., 2013; Ali et al., 2018).

Rewards are provided by companion plants artificially incorporated within cropping systems. Companion plants have specific functional traits which may enhance the settlement and population growth of pests' natural enemies (Gurr et al., 2015, 2017; Perovic et al., 2018). They are also known as ecosystem service providers (Kremen, 2005) or secondary plants (Parolin et al., 2012). They may provide complementary food resources, such as pollen and nectar, for targeted natural enemies (Baggen et al., 1999; Li et al., 2015), or resources for alternative hosts or prey of natural enemies (banker plants: Bugg \& Waddington, 1994; Huang et al., 2011). They may also provide shelter or reproductive sites for natural enemies and attract them through visual and olfactory cues, drawing them to suboptimal or disturbed environments such as crop fields (Beane \& Bugg 1998; Zhao et al., 2017; Gurr et al., 2017; Perovic et al., 2018). Frequently used companion plants include marigold (Calendula officinalis; Martínez-Uña et al., 2013; Zhao et al., 2017; Nemec et al., 2016) and sweet alyssum (Lobularia maritima; Gontijo et al., 2013; Brennan, 2016). In those studies, these companion plants were considered as abundant pollen and nectar providers, and they mostly attracted hoverflies and hemipteran bugs, resulting in a successful control of arthropod pests. In a preliminary experiment, we fed adults of Propylea japonica (Coccinellidae) with Calendula officinalis flowers along with ad libitum Mizus persicae aphid nymphs in a laboratory experiment, and we measured a 1.43- and 1.34-fold increase in their longevity and fecundity, respectively (Fig. S1). This highlights the potential for C. officinalis to act as a reward to coccinellids in crop fields.

Simpson et al. (2011a) implemented the attractand-reward strategy in various crops (sweetcorn, broccoli and grapevine) which were treated with synthetic HIPVs (including MeSA and methyl jasmonate) and surrounded by buckwheat (Fagopyrum esculentum) as a companion plant providing nectar resource. They found that natural enemies (parasitoids and predators) were more abundant near plants treated with synthetic HIPVs than near nontreated plants, which resulted in efficient top-down regulation of pests and reduced crop damage. Other implementations of this strategy yielded mixed success (Simpson et al., 2011b; Salamanca et al., 2018), highlighting the importance of optimizing the provision of companion plants and synthetic HIPVs in crop fields. Both companion plants and synthetic HIPVs may affect non-target species. For instance, they may attract other pests as well as non-target natural enemies and higher trophic levels (Wäckers et al., 2007; Orre et al., 2010; Parolin et al., 2012; Orre-Gordon et al., 2013), which may in turn increase intra-guild predation between natural enemies (Jonsson et al., 2008) and fail to increase crop productivity (Salamanca et al., 2018).

Much work remains to understand the influence of landscape composition on the densities of pests and their natural enemies at various spatial scales (Gurr et al., 2017; Karp et al., 2018). Floral resource provisioning such as flower strips within and around fields has been shown to increase the abundance of natural enemies and reduce pest pressure in neighbouring fields (Tschumi et al., 2016; Balzan et al., 2016). In practical implementations of attract-and-reward strategies, both floral resources and HIPVs are manipulated within fields, and how companion plants with respect to synthetic HIPV dispensers are spatially arranged may influence the movement of natural enemies, because they signal for different resources and elicit different foraging behaviours (Landis et al., 2000). Once inside crop fields, natural enemies use HIPVs to locate prey nearby, but may be unable to detect them if prey-specific signals are too weak and/or prey too distant from HIPVs emitters (Vet \& Dicke, 1992). They then might turn to alternative resources, such as companion plants. On the contrary, too high concentrations of synthetic HIPVs may repel natural enemies (van Wijk et al., 2008), and also induce neighbouring plants' own production of volatiles (Delanay et al., 2013), resulting in confusing air signals to targeted natural enemies (Kaplan \& Lewis, 2015). Finally, they might become habituated to HIPVs (i.e., learn to dissociate HIPVs from the presence of prey), and disperse away (Kaplan, 2012; Kaplan \& Lewis, 2015; Lucchi et al., 2017). The overlooked spatial arrangement of companion plants and synthetic HIPVs within fields might be key to improve the success of attract-andreward strategies (Kaplan \& Lewis, 2015). 
In the present study, we investigated how the spatial arrangement of synthetic MeSA dispensers and companion plants C. officinalis within apple orchards affected the attraction and persistence of ladybirds Propylea japonica, and the subsequent impact on aphid Aphis citricola populations. By sucking leaf phloem and producing honeydew, aphids drastically reduce apple tree photosynthesis and yields (Yin et al., 2013). Propylea japonica is among the most abundant species of naturally occurring ladybirds in Northern China, and is able to efficiently control aphids in cotton fields (Wu \& Guo, 2005; Lu et al., 2012; Ali et al., 2016). In preliminary experiments, we showed that C.officinalis companion plants alone did not significantly improve aphid control in orchards, while MeSA alone yielded a $30 \%$ reduction in aphid densities relative to control in the long term (Fig. S2). However, the initial aphid population growth was not prevented. We also found that clustering MeSA dispensers and companion plants did not improve aphid control compared with an untreated orchard (Fig. S3). In the present study we tested how two contrasting spatial arrangements of MeSA dispensers and companion plants - MeSA dispensers inside a block of target apple trees and companion plants around it, or vice versa - affected the density of ladybird and aphid populations inside the block. To gain insights into the mechanisms underlying observed differences in insect densities, we conducted three indoor experiments to measure the long-distance flight capacities (in a flight mill), the short distance attraction (in an olfactometer), and the short-distance foraging behaviour of $P$. japonica adults (in a windtunnel) in response to the presence of MeSA dispensers and companion plants.

\section{1 | MATERIALS AND METHODS}

\subsection{MeSA dispensers and companion plants}

Methyl salicylate (MeSA, 99\% purity, ZZStandard, Shanghai, China) was diluted in n-hexane (97\% purity, Yufeng, Liaoyang, China) at a low (0.2 $\mu \mathrm{g}$ MeSA dissolved in $0.1 \mathrm{~mL}$ hexane) and a high concentration (200 $\mu \mathrm{g}$ in $0.1 \mathrm{~mL}$ hexane), following the protocol of Petterson et al. (1994). In field experiments, we used 1.5mL polyethylene bottles of high-concentration MeSA and with a 1.0-mm-diameter hole in the cover to allow evaporation in the ambient air. In indoor experiments, we used either 1.5-mL bottles of low-concentration MeSA (flight mill and wind-tunnel) or filter paper cards $(1.0 \times$ $4.0 \mathrm{~cm}$ ) loaded with $2 \mathrm{~mL}$ of high-concentration MeSA and evaporated for $5 \mathrm{~min}$ to remove solvent (olfactometer; De Boer \& Dicke, 2004). Companion plants Calendula officinalis var. Kablouna were obtained from the SinicHorticulture and Lower Co. Ltd, Beijing, China, from seeds collected during the previous season. Seedlings were started in plastic trays and individually transplanted in plastic pots (height $20 \mathrm{~cm}$, diameter $13 \mathrm{~cm}$ ) when they had three to four true leaves. After 2025 days, the plants were $\sim 20 \mathrm{~cm}$ tall and the terminal bud was removed to ensure flower production. Two weeks later, they were blooming and could be used in our experiments starting in April 2016. They were maintained in a greenhouse to ensure constant flowering throughout the season.

\section{2 | Orchard experiment: spatial arrangement of HIPV dispensers and rewards}

Nine organic apple orchards were surveyed in the Changping County, Beijing, China in 2016 (Fig. S4, Table S2). Each orchard contained more than 1,000 mature apple trees (Malus pumila cv. Fuji) planted in 2006. Two different treatments (T1 or T2) were applied on a $5 \times 5$ block of 25 apple trees of similar age at the centre of each orchard (Fig. 1). In T1, MeSA dispensers and companion plants were placed inside and around the block of trees, respectively (spacing is shown in Fig. 1). In T2, the opposite spatial arrangement was used. T1 was applied in orchards \#1, \#2 and \#3, while T2 was applied in orchards \#4, \#5 and \#6 and orchards \#7, \#8, \#9 were controls (no treatment; Fig. S4). In all orchards, agricultural practices were conducted according to the USDA-Organic standard (\#7-CFR-Part-205, certified by ECOCERT ${ }^{\circledR}$ ), which specifies tree fertilization with organic botanic/microorganism formulations, no pesticide application, and weed removal twice a month. Each MeSA dispenser was placed in a plastic box $(3 \times 3 \times 3$ $\mathrm{cm})$ covered with a 50-mesh plastic fabric net to block rainfall but not ventilation. The MeSA boxes were placed at each site in early May and partially buried, leaving $3 \mathrm{~cm}$ above the ground surface. The MeSA dispensers inside the boxes were replaced with new ones weekly. Potted companion plants with four to six open flowers each were placed in each site at the same time. They were renewed every 10 days, during which they were watered every two days and had at least four open flowers.

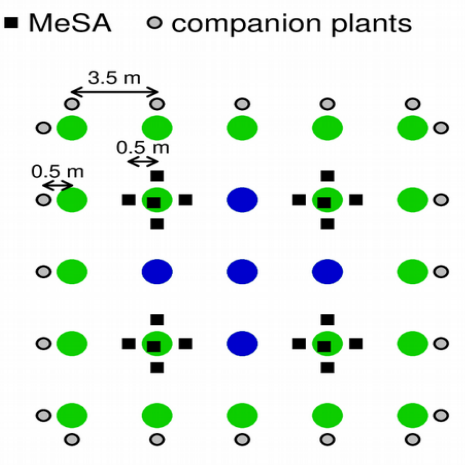

T1 target trees

Oot
FIGURE 1 Treated block of 25 trees in orchards: spatial arrangement of MeSA dispensers and C. officinalis companion plants in T1- and T2-treated orchards. MeSA dispensers and companion plants overlaid on trees were placed $10 \mathrm{~cm}$ from the base of the tree. 
From mid April (ten days before the treatment application) to mid August, P. japonica ladybird and A. citricola aphid populations were surveyed once a week on five target trees at the centre of each treated block (Fig. 1). Each sampling day, four randomly selected young branches per target tree (length $65-70 \mathrm{~cm}$ ) were visually inspected and all ladybirds (adults and larvae) and aphids (adults and juveniles) were counted. Visual inspection is the preferred method in Chinese orchards, as it provides repeatable and non-destructive insect population monitoring at affordable costs (Wang, S., personal obs.). At the time of harvest, commercially acceptable apples from the treated block of 25 trees in each orchard were weighed, as a measure of yield.

We analysed the short-term and long-term influences of the contrasting spatial arrangements of MeSA dispensers and companion plants on the ladybird and aphid population dynamics in Weeks 3-5 and Weeks 9-18 of the experimental period, respectively. Weeks 1-2 corresponded to the seasonal immigration of ladybirds from wild habitats into orchards (2008-2014 historic records from Wang, S.). Weeks 3-5 corresponded to the short-term response of insect population dynamics to the treatment, applied five days before the sampling of Week 3. Weeks 9-18 corresponded to the stabilising phase, and coincided with two to three generation cycles of $P$. japonica ladybirds, which have a life cycle very similar to that of Harmonia axyridis (Wang, S. personal obs.; Wang et al., 2011). To account for correlation among samples taken repeatedly from the same five trees per orchard, a random subject effect of tree number nested in the orchard was first included in Generalized Linear Mixed models, with a negative binomial distribution to account for the non-normality of count data. This distribution was chosen against a Poisson distribution based on AIC/BIC criteria. The random effects were systematically estimated to zero in the models, meaning that residual deviance completely accounted for the variation in data. Therefore, we simply used GLMs. Since the treatment significantly affected population dynamics, multiple comparisons of means were performed by Tukey's HSD (function 'glht' from R library 'multcomp'). Yield data were analysed by performing a one-way ANOVA on the treatment, and residuals were normally distributed. All statistical analyses were performed using $\mathrm{R}$ version 3.2.3 (R Core Team, 2015).

\section{3 | Indoor experiments: olfactometer, flightmill and wind-tunnel}

\subsection{1 | Insects}

Five hundred pairs of $P$. japonica adults were collected from an alfalfa field at Beijing Academy of Agriculture and Forestry Sciences (BAAFS, Beijing, China) on April 2016. The ladybirds were maintained in the Entomology Research Laboratory of the Institute of Plant and Environment Protection, BAAFS at a density of 30-40 pairs per cage $(40.0 \times 40.0 \times 55.0 \mathrm{~cm}$, made of 40 -mesh plastic net and aluminium alloy frames). They were fed ad libitum with reared Aphis citricola (Hemiptera:
Aphididae) as well as young horse bean shoots. Ten white paper sheets per cage $(10.0 \times 3.0 \mathrm{~cm})$ were provided as oviposition substrate. Paper sheets were transferred daily into another cage where hatched juveniles were maintained until adulthood with the same diet as described above. Newly emerged adults were transferred daily into new cages at the same density as above and fed ad libitum. Ten-day-old, mature adult ladybirds were selected for the tests. Environmental rearing conditions were $\mathrm{T}=23{ }^{\circ} \mathrm{C}, \quad \mathrm{RH}=65 \%$, photoperiod $=16 \mathrm{~L}: 8 \mathrm{D}$ at 1000 lux.

\subsection{2 | Flight mill test: Long-distance flying capacities}

We tested how the presence and spatial arrangement of MeSA dispensers and companion plants affected the flight capacity of $P$. japonica adults, using a flight mill device in sunny, controlled greenhouse conditions. Insects flying a longer distance in these experiments are likely to disperse a greater distance in natural conditions (Bradley \& Altizer, 2005; Maes et al., 2014). Flight mill experiments are also used to test the impact of environmental cues on insects' flying capacities (Salom \& McLean, 1991; Rouyar et al., 2015). The flight mill was composed of 16 independent channels, allowing us to test 16 individuals simultaneously (SY2-16A, Jiaduo Equip., Anyang, China). The channels were $15 \mathrm{~m}$ apart from each other to avoid visual and olfactory interference. Each channel was composed of two titanium arms (upper arm length: $40 \mathrm{~cm}$; lower arm length: $5 \mathrm{~cm}$ ) fixed to a common axis forcing a synchronous rotation with standardized perturbations (Taylor et al., 2010; Ribak et al., 2017). The tested insect was attached to one end of the upper arm with a nylon fabric thread (diameter: $0.2 \mathrm{~mm}$, length: $2.5 \mathrm{~cm}$ ), and a counterweight was attached to the other end. We chose ladybirds of very similar body size, so that the counterweight was adjusted only once at the beginning of the experiment, at the average ladybirds' weight. The number of revolutions, the flight distance $(\mathrm{km})$, the flight duration ( $\mathrm{min}$ ) and the average flight speed ( $\mathrm{m} / \mathrm{min}$ ) were recorded and calculated automatically in each channel. Each test lasted 12 hours.

Five treatments were applied, with a varying combination of olfactory cues: (1) two companion plants; (2) two MeSA dispensers; (3) one companion plant and one MeSA dispenser placed together ( $<5 \mathrm{~cm}$ apart); (4) one companion plant and one MeSA dispenser separated; and (5) control (no environmental cue). Each plant had exactly three open flowers. The MeSA dispensers were positioned at a height comparable to plants, ensuring that chemical cues were emitted from similar positions. Cues were placed at $75 \mathrm{~cm}$ from the flight mill's rotating axis at opposite positions (except in Treatment 3). Each treatment was replicated 20 times with a new ladybird individual, for a total of 100 ladybirds. Companion plants and MeSA dispensers were renewed each time.

We analysed the flight distance, the flight duration and the square root-transformed average flight speed using a MANOVA with a Pillai test with treatment (presence of different environmental cues) as a fixed effect. We then performed Tukey's HSD tests to compare means for each variable. 


\subsection{3 | Olfactometer test: short-distance attraction}

We tested whether adult ladybirds were attracted by MeSA and by the odour of companion plant C. officinalis, isolated or together, in a four-arm olfactometer (CT10 Camsonar; Kunming, China), following Vet et al. (1983) and $\mathrm{Li}$ et al. (2015). Ambient air was vacuumed from the bottom of the olfactometer's central arena at $1.5 \mathrm{~mL} / \mathrm{min}$. Each arm was connected using Teflon tubing to a series of four glass vials (height $18 \mathrm{~cm}$, diameter $9.5 \mathrm{~cm}$; except second vial: height $35 \mathrm{~cm}$, diameter $18 \mathrm{~cm}$ ). The first vial collected the ladybird choosing that arm. The second contained the odour source, the third contained activated charcoal to purify air, and the last vial contained distilled water to humidify air. Air flowed at $1 \mathrm{~mL} / \mathrm{min}$ inwards from the last vial to the central arena. The odour sources in the four arms were: (i) MeSA dispenser; (ii) potted companion plant with exactly three open flowers carefully placed in the vial; (iii) MeSA dispenser and plant; or (iv) no MeSA dispenser or plant (control). The central arena of the olfactometer was kept in a dark chamber with a 24W lamp placed above to provide uniform light and avoid visual interference. Behavioural observations were conducted at $22-25{ }^{\circ} \mathrm{C}$. The experiment consisted of 20 replicates of 60 ladybirds, starved for eight hours prior to the experiment. They were introduced one at a time in the walking arena. A new piece of filter paper was placed on the arena floor after each 60-ladybird replicate. The olfactometer was also cleaned with soap-water and entirely rinsed with hexane, and odour sources were replaced with fresh ones (new MeSA dispensers and new plants). After 5 min to allow air flow to stabilize, a new ladybird was placed in the walking arena. The position of the four different odour sources was randomized in the four arms between each replicate. As soon as the ladybird entered one arm, it fell in the sampling chamber where it was collected and the chosen arm was recorded, before introducing a new ladybird into the olfactometer.

The relative attractiveness of the different olfactory stimuli in the four-arm olfactometer was estimated using the 'prop.multinom.test' function of the $\mathrm{R}$ library RVAideMemoire. This function builds multinomial loglinear models on the number of ladybirds choosing each arm (Ricard \& Davison, 2007; Davison \& Ricard, 2011), and performs Wald tests with the Benjamini and Hochberg (1995) correction method for comparing multiple P-values (p.adust $=$ "fdr"). The mean proportions and standard errors were calculated with the 'prop.multinom' function which relies on the same methodology.

\subsection{4 | Wind-tunnel: short-distance foraging behaviour}

We measured the short-distance foraging behaviour of adult ladybirds in a wind-tunnel in the presence of MeSA dispensers, companion plants, and A. citricola prey. The wind-tunnel had three contiguous chambers (Fig. S5). The position of the MeSA chamber and the companion plant chamber (right vs. middle), and the presence or absence of prey in the left chamber were varied among treatments in a full factorial design, with 15 replicates per treatment. Five MeSA dispensers and three companion plants each with five fully open flowers were placed in boxes under their respective main chambers and connected to them with a fine dark mesh masking plants' visual cues (Fig. S5). In treatments with prey, 1,000 A. citricola second- or third-instar nymphs were placed in the prey chamber (left), in a plastic box covered with a dark fine mesh to prevent them from being accessible or visible to ladybirds; however they could smell each other. The number of MeSA dispensers, companion plants and aphids was established based on maximum sensitivity of ladybirds as tested in a preliminary experiment. Thirty randomly-selected 10-day-old $P$. japonica adults were introduced into the releasing chamber for each replicate. A $2.0 \mathrm{~L} / \mathrm{min}$ airflow was then established from the prey chamber towards the release chamber to spread olfactory cues and avoid their accumulation and degradation in the wind-tunnel. The walls separating the chambers were removed after the airflow had stabilized (about $30 \mathrm{~s}$ ) to allow the ladybirds to freely disperse in the three contiguous chambers. The number of ladybirds staying in each chamber was recorded 20, 40 and 60 min after the walls' removal. At the end of each 60-minute sequence, all insects, the MeSA dispensers and the companion plants were removed from the wind-tunnel, and all sections of the tunnel were cleaned with distilled water and hexane $(95 \%, \mathrm{v} / \mathrm{v})$.

We examined how the proportions of ladybirds in each of the three chambers of the wind-tunnel varied through time, depending on whether they first entered the MeSA chamber or the plant chamber, and the prey was present or absent. Based on the olfactometer and flight mill experiments, we hypothesized that MeSA was more attractive than companion plants and ladybirds would thus always focus on MeSA dispensers first. Then, they would try to find prey if present, and otherwise find alternative food resource. Therefore, the proportion of ladybirds in the MeSA chamber should always decrease through time, while the proportions in the prey and plant chambers should increase when prey are present versus absent, respectively. We also hypothesized that ladybirds used the strong MeSA signal to locate aphid prey, which typically cause emissions of HIPVs (including MeSA) in attacked plants. Therefore, we expected that ladybirds would find aphids faster if they are located close to the MeSA chamber (i.e., in treatments with the MeSA dispenser in the middle chamber), but the spatial arrangement of the MeSA dispenser and the companion plant should have no effect on the distribution of ladybirds in the absence of prey. We performed a repeated measures analysis to account for the correlation between observations made at 20,40, and $60 \mathrm{~min}$ in the same replicate, and a random subject effect (replicate) was included. We performed two sets of Generalized Linear Mixed Models (function 'glmer' in the library 'Ime4) with a binomial distribution and a logit link function. First, we analysed the proportion of ladybirds in the MeSA chamber versus the other two (total proportion of ladybirds in prey chamber plus plant chamber), and second the proportion of ladybirds in the plant chamber versus the other two (total proportion of ladybirds in prey chamber plus MeSA chamber). In each set of tests, the fixed effects were the presence/absence of prey, the spatial arrangement of MeSA and companion plants in the 
middle versus right chamber, and time (implemented as a fraction of hour), as well as all second-order interactions between fixed effects. Generally multinomial rather than binomial tests are expected for this kind of experiment; however they are intrinsically difficult to interpret and the implementation of pseudo-replication worsens this problem, leading us to use GLMMs. The significance of second-order interactions was estimated by a type-II model comparison based on chi-square tests. The most likely model was obtained by removal of the non significant interaction, and we verified that residuals were normally distributed using Shapiro-Wilk tests. Since we conducted two sets of tests on the same data set, we adjusted the paired $P$-values from the same factors in the two best models using the Benjamini \& Hochberg (1995) to reduce the risk of type-I errors (false detection).

\section{3 | RESULTS}

We tested the impact of the spatial arrangement of MeSA dispensers and companion plants in orchards on the efficacy of aphid control by ladybirds. The treatment significantly affected population dynamics of ladybirds and aphids both on the short-term and on the long-term (Fig. 2; Tables 1, S3). In the short-term, treatment T1 (MeSA dispensers inside the block of 25 trees and companion plants around it) resulted in a 1.5-fold increase in ladybirds counts compared with T2 (MeSA dispensers around the block and companion plants inside it), and a 4.6-fold increase compared to control orchards. However, the ladybird population rapidly decreased in T1-treated orchards and stabilised around 0.75 ladybirds per branch after Week 8, compared with 1.73 and 1.59 ladybirds per branch in T2-treated orchards and control orchards, respectively. Aphid populations were regulated faster in $\mathrm{T} 1$, resulting in a 2-fold and a 4-fold decrease in aphid counts in T1 compared with T2 and control, respectively over Weeks 3-5. After Week 9, aphid counts stabilized around 20 and 60 per branch in T1 and T2, respectively, while they fluctuated between 300 and 700 per branch in control orchards. The treatment significantly affected yields $\left(\mathrm{F}_{2,6}=52.75, P<0.001\right.$; Fig. S6; Table S3), with yields 1.07 and 1.16 times higher in T1-treated blocks than in T2-treated and control blocks, respectively.

TABLE 1 Impact of the spatial arrangement of MeSA dispensers and companion plants in orchards on the population dynamics of ladybirds and aphids

\begin{tabular}{lccc}
$\begin{array}{l}\text { Fixed } \\
\text { effects }\end{array}$ & $\begin{array}{c}\text { Deviance, } \\
\text { Residual } \\
\text { Deviance }\end{array}$ & $\begin{array}{c}\text { df, Residual } \\
\text { df }\end{array}$ & P-value \\
\hline$\underline{\text { Short-term }}$ & & & \\
\hline $\begin{array}{l}\text { Ladybirds } \\
\text { Aphids }\end{array}$ & 174,606 & 2,537 & $<0.001$ \\
& 445,570 & 2,537 & $<0.001$ \\
Long-term & & & \\
\hline Ladybirds & 126,1858 & 2,1797 & $<0.001$ \\
Aphids & 5965,1885 & 2,1737 & $<0.001$ \\
\hline
\end{tabular}

Note. Generalized Linear Models were used, with a negative binomial distribution and the spatial arrangement of MeSA dispensers and companion plants as a fixed effect.

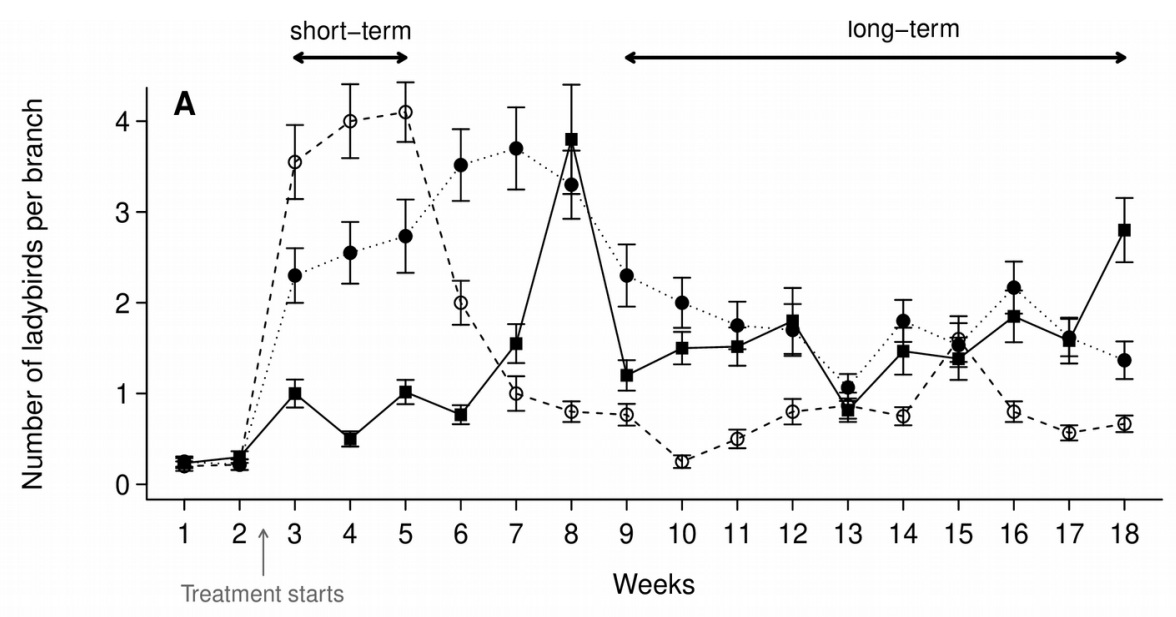

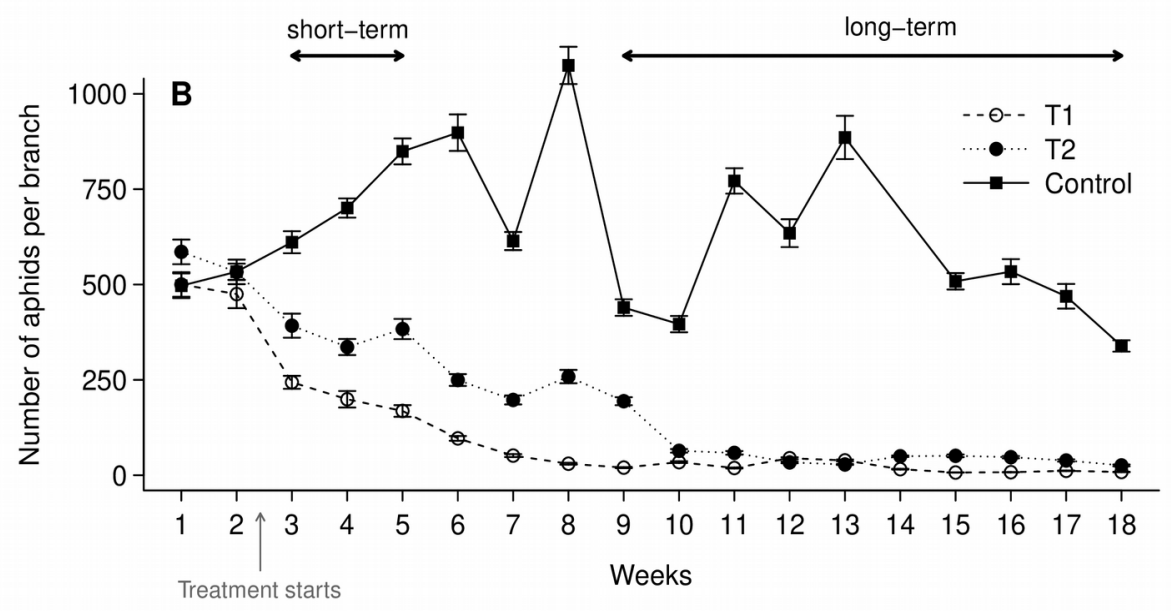

FIGURE 2 Impact of the spatial arrangement of MeSA dispensers and C. officinalis companion plants on the population dynamics of (A) P. japonica predatory ladybirds (adults and larvae) and (B) A. citricola aphids (adults and juveniles). Mean numbers ( \pm SE); $N=60$ (three orchards per treatment, five target trees per orchard, four branches per target tree). T1: MeSA dispensers inside the block and companion plants around it; $\mathrm{T} 2$ : opposite arrangement; Control: no treatment 
We then conducted indoor experiments to gain insights on the mechanisms underlying the observed differences between treatments. Specifically, we measured the long-distance flying capacities of adult ladybirds in a flight mill, the short-distance attraction in an olfactometer, and the short-distance foraging behaviour in a wind-tunnel.
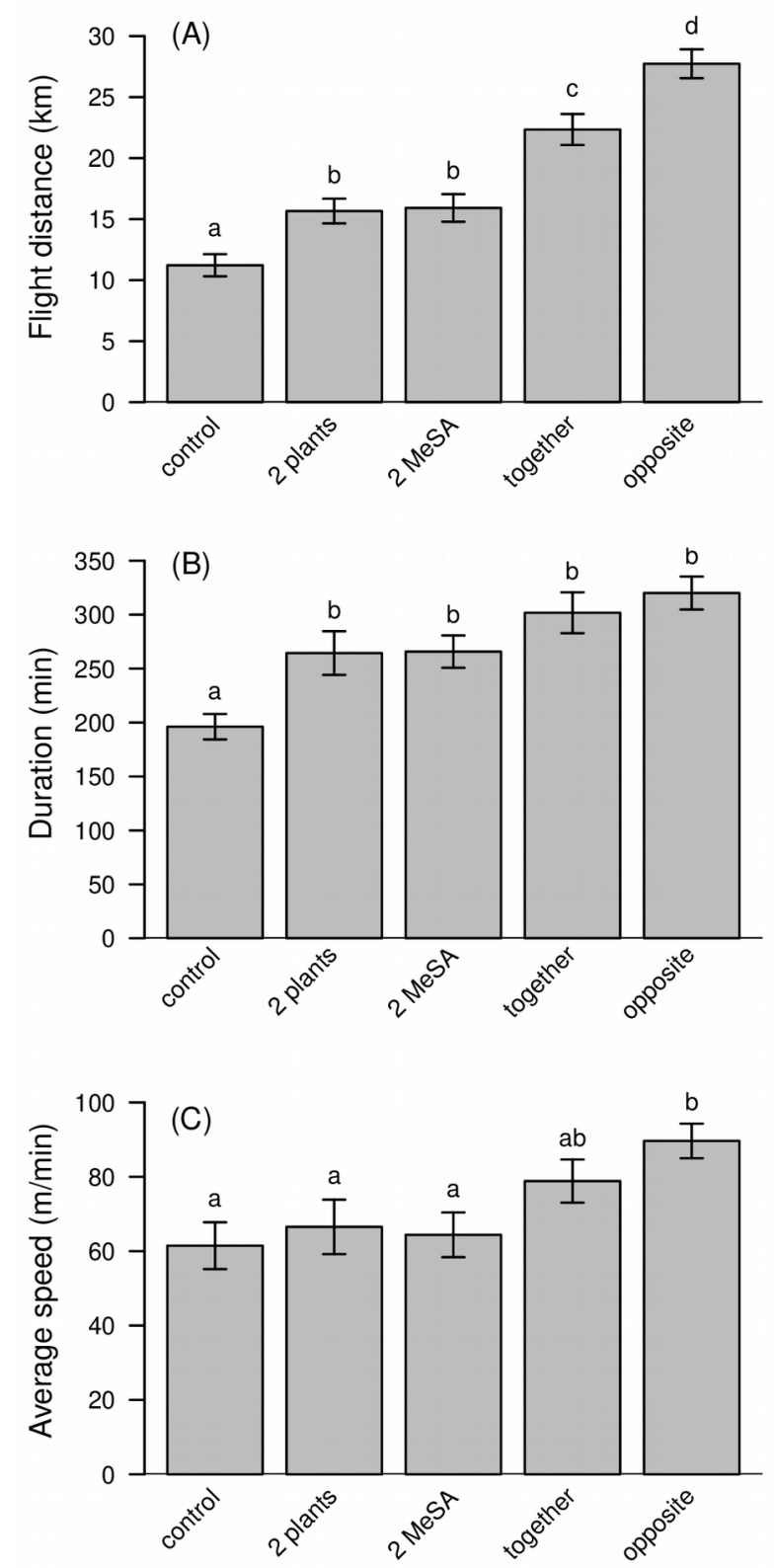

FIGURE 3 Flight distance (A), duration of flight (B) and average speed (C) of ladybirds in the flight mill experiment, exposed to different environmental cues (means $\pm \mathrm{SE}$ ). Control: no cue; 2 plants: two companion plants at opposite positions; 2 MeSA: two MeSA dispensers at opposite positions; together: one companion plant and one MeSA dispenser at the same position; opposite: one companion plant and one MeSA dispenser at opposite positions. Different letters above bars represent significantly different means as estimated by Tukey's HSD tests (Tables S5-7).

We found that the presence, nature and position of MeSA dispensers and companion plants in the flight mill experiment significantly affected ladybirds' flight capacities (Pillai $=0.74$, df $=4,95, P<0.001$ ). $\quad$ Flight capacities were significantly improved when the MeSA dispenser and the companion plant were provided as compared to the control or treatments with two identical olfactory sources. This response increased when the dispenser and the plant were placed opposite to one another rather than together in the flight mill experiment (Fig. 3, Tables S5-7).

In the olfactometer experiment, we found that both MeSA and C. officinalis volatiles attracted adult ladybirds. The combination of the two was the most attractive, followed by a MeSA dispenser alone, then the companion plant and finally the control (no scented cue; Fig. 4, Table S8).

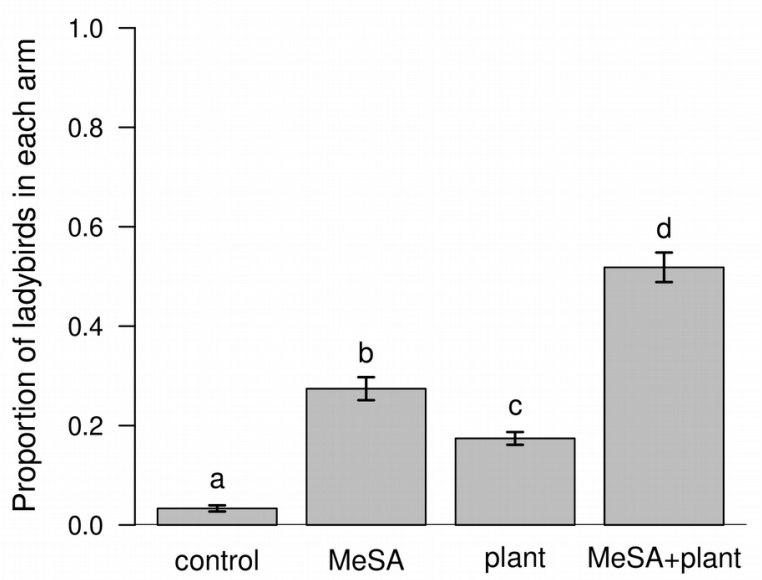

FIGURE 4. Proportion of ladybirds in each arm of the olfactometer connected to different olfactory stimuli. The different letters above bars represent significantly different proportions as estimated by the Wald tests (Table S8).

In the wind-tunnel experiment, we found that the interaction between the presence/absence of prey and time significantly affected both the proportion of ladybirds in the MeSA chamber (MeSA vs. prey + plant) and the proportion of ladybirds in the plant chamber (plant vs. MeSA + prey; Fig. 5; Table 2). The proportion of ladybirds in the MeSA chamber (vs. prey + plant) was also affected by the interaction between position and prey, while the proportion of ladybirds in the plant chamber (vs. MesA + prey) was affected by the interaction between position and time. Basically, as shown by the coefficients of the best models for each set of tests (Table 2), ladybirds first went to the MeSA chamber (positive intercept for MeSA vs. prey + plant and negative intercept for plant vs. MeSA + prey). In the absence of prey, they left the MeSA chamber for the plant chamber. In the presence of prey, they left the MeSA chamber for the prey chamber, and the position of the MeSA vs. plant chamber affected how quickly they found prey: they tended to search for prey close to MeSA dispensers, and hence spent more time in the MeSA chamber when it was in the right position (i.e., distant from the prey chamber). 


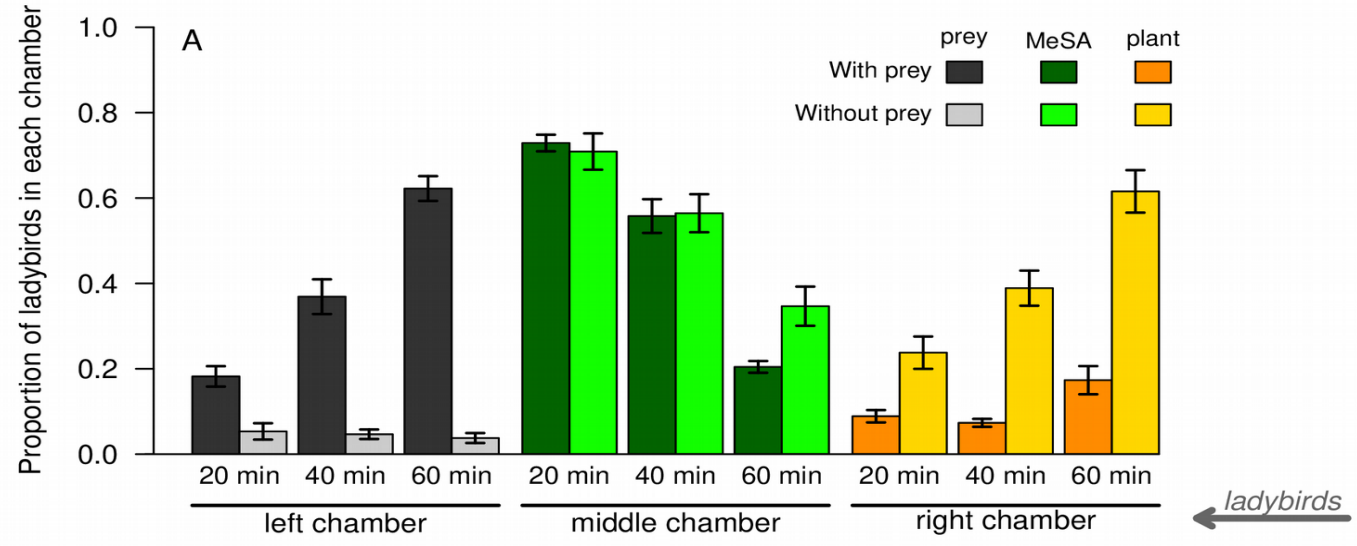

FIGURE 5 Proportion of ladybirds in the three chambers of the windtunnel through time. The bottom-right arrows indicates in which side the ladybirds were introduced. The MeSA dispenser and the companion plants were alternatively placed in connection with the middle versus right chambers (A and B panels).
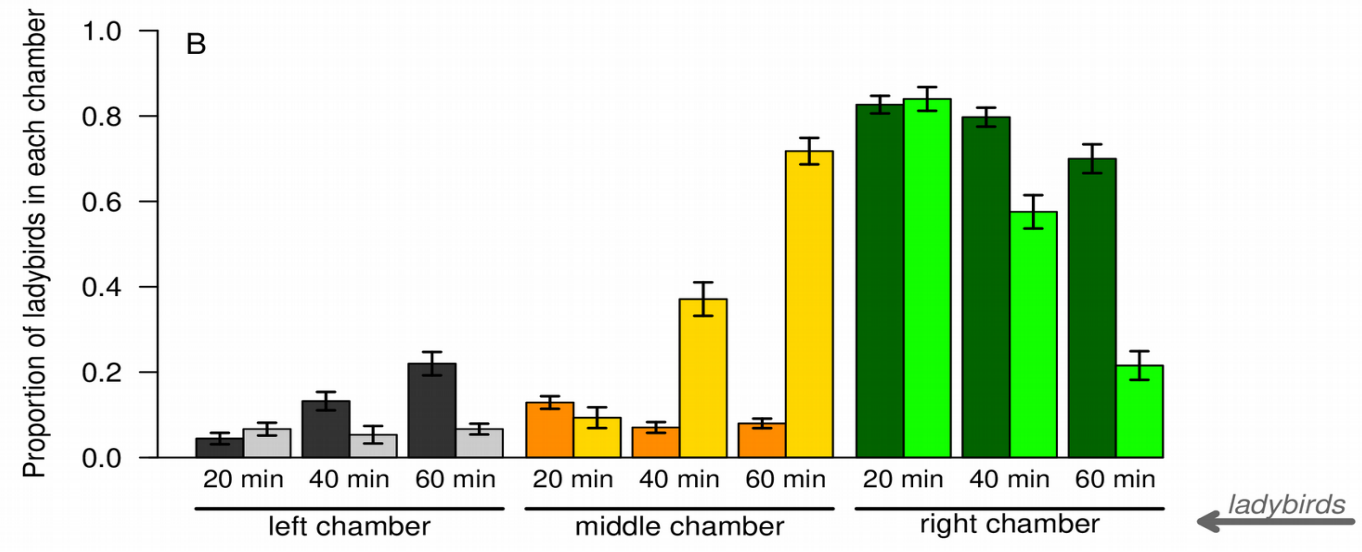

TABLE 2 Effects of the presence of prey, the position of MeSA dispensers and companion plants, and time on the proportions of ladybirds in the three chambers of the wind-tunnel. GLMMs were used with a binomial distribution and the replicate number as random effect.

\begin{tabular}{lccc}
\hline Fixed effects & $\mathbf{X}^{2}$ & df & $P$-value \\
\hline MeSA vs. Prey+Plant & & & \\
Position:Time & 0.078 & 1 & 0.78 \\
Position:Prey & 52.06 & 1 & $<0.001$ \\
Prey:Time & 12.79 & 1 & 0.00035 \\
Plant vs. MeSA+Prey & & & \\
Position:Time & 6.73 & 1 & 0.019 \\
Position:Prey & 0.14 & 1 & 0.71 \\
Prey:Time & 121.13 & 1 & $<0.001$ \\
\hline
\end{tabular}

Note. Best model's coefficients for MeSA vs. Prey+Plant:

Intercept: 2.39; Prey[Yes]: -0.77; Position[Plant_middle]: 0.02; Time: 3.29*Time; Prey[Yes]:Position[Plant_middle]: 1.36;

Prey[Yes]:Time: $0.84 *$ Time

Best model's coefficients for Plant vs. MeSA+Prey: Intercept: -2.52 Prey[Yes]: 0.43; Position[Plant_middle]: -0.65; Time: 3.19*Time; Position[Plant_middle]:Time: 0.72*Time; Prey[Yes]:Time: -3.23*Time

\section{4 | DISCUSSION}

In the present study, we applied an attract-and-reward strategy and investigated how the spatial arrangement of MeSA dispensers and companion plants affected the densities of ladybird and aphid populations in apple orchards. When MeSA dispensers were placed inside a block of trees and companion plants around it (T1), aphid populations were more strongly controlled inside the block, resulting in higher yields, compared with nontreated orchards. The opposite spatial arrangement (T2: MeSA around the block and companion plants inside it) resulted in intermediate control of aphid populations due to lower densities of ladybirds (Fig. 2). To gain insights on the mechanisms underlying such difference, we conducted three indoor experiments. The flight mill and olfactometer experiments showed that MeSA and companion plants synergistically attracted ladybirds (Figs. 3-4). The wind-tunnel results suggested that ladybirds used MeSA as an indicator of nearby prey, and that the presence of prey negatively affected their attraction to companion plants (Fig. 5). This possibly explains why the control of aphid populations was faster in T1-treated orchards.

The attract-and-reward strategy resulted in a rapid regulation of aphid populations, preventing exponential growth observed in control orchards (Fig. 2), and contrary to our preliminary experiment relying on MeSA-only treatment (Fig. S2). Spatially separating MeSA dispensers and companion plants allowed a stronger control of aphid populations compared with MeSA and companion plants being clustered in treated orchards (Fig. S3). One reason might be a stimulation of ladybirds' flight activity (Fig. 3) and foraging behaviour (as compared to clustered cues), increasing the probability that ladybirds would find aphids. We measured an immediate positive impact of a large number of ladybirds being attracted to orchards on the regulation of aphid populations in the short term. The timing of natural enemies' movement into crop fields relative to pests' population dynamics and outbreaks is indeed crucial (Kean et al., 2003; Brewer et al., 2017). In the short term, higher densities of ladybirds were measured in T1compared with T2-treated orchards, resulting in a faster decrease in aphid densities. In T1-treated orchards, MeSA likely served as a reliable cue for finding prey nearby target trees, as shown in the wind-tunnel 
experiment (Fig. 5). The subsequent faster decrease in ladybird densities in $\mathrm{T} 1$ compared with $\mathrm{T} 2$ might have been due to food resource shortage inside the treated block, partly because of the faster decrease in aphid population densities, and partly because of the absence of plant resources from companion plants. On the long term aphid populations stabilized below 100 aphids per branch in both $\mathrm{T} 1$ and $\mathrm{T} 2$ compared with 500 aphids per branch in control (Fig. 2), showing the consistent long-term regulation of aphid populations in attract-and-reward strategies with a spatial separation of MeSA dispensers and companion plants. This emphasizes the potential of such strategies. In comparison our preliminary experiments with a clustered spatial arrangement of MeSA dispensers and companion plants did not improve aphid control (Fig. S3). When we used MeSA alone or companion plants alone, aphid populations stabilized to only 300 and 400 aphids per branch, respectively, in the long term (Fig. S2).

The $\mathrm{T} 1$ spatial arrangement is therefore a more promising biocontrol strategy for several reasons. First, it attracted high densities of ladybirds in the short term, leading to a faster regulation of aphids populations and higher apple yields. Brewer et al. (2017) found that yield loss was increased when populations of the sugarcane aphid Melanaphis sacchari grew rapidly in sorghum fields, emphasizing the importance of pest short-term regulation of pests. Second, since ladybirds drawn to orchards by MeSA may have difficulty locating aphids, the companion plants around the treated block in T1 may have provided a "belt" of alternative resources until they find alternative prey in target trees. Third, ladybirds remained at lower densities in target trees in $\mathrm{T} 1$ compared with $\mathrm{T} 2$ in the long term. This outcome is especially important in the context of CBC for avoiding the negative impacts of attracting natural enemies after target pest populations are controlled. If predators remain in the treated area too long, they may destabilize the ecosystem by attacking alternative non-target prey (Simberloff \& Stiling, 1996; Louda et al., 2003; Ricciardi \& Simberloff, 2009). Stephens et al. (1998) demonstrated that sowing buckwheat in orchards as shelter plants increased the biodiversity of arthropods but not that of beneficial insects. Finally, T1 allowed a treatment by blocks at the scale of the orchard without reducing pest control inside blocks, as opposed to T2.

Both MeSA and C.officinalis scent attracted $P$. japonica in our olfactometer experiment, with MeSA being more attractive than C. officinalis (Fig. 4). The HIPV MeSA has been shown to attract natural enemies of herbivorous arthropods, including predatory mites, hoverflies, lacewings, mirid bugs, ladybirds and parasitoid wasps, under laboratory and field conditions (James, 2003; Rodriguez-Saona et al., 2011; Braasch et al., 2012; Gadino et al., 2012; Gençer et al., 2017). The literature on the attractiveness of semiochemicals from C. officinalis to ladybirds or other natural enemies is limited, although semiochemicals from other plant species have been shown to attract ladybirds (Ninkovic \& Pettersson, 2003; Francis et al., 2004; Qi et al., 2008). Interestingly, olfactory cues from both sources provided together in the olfactometer synergistically attracted ladybirds (Fig. 4), enhancing the potential of their combined use in an attract-and-reward strategy for P. japonica.

The synergistic attraction of MeSA and companion plants was also clear in the flight mill experiment: the flight capacities of adult ladybirds were enhanced, possibly through stimulation of their foraging behaviour (Fig. 3). In comparison with parasitoid wasps or moths, the flight behaviour of ladybirds has been less investigated, with the exception of long distance movement, such as overwinter migration (Ricci et al., 2005; Wang et al., 2011). Prey semiochemicals and flower volatiles have been shown to trigger the long-range flight behaviour of predatory arthropods (Salom \& McLean, 1991; Rouyar et al., 2015). In the field, the stimulation of ladybirds' foraging behaviour by multiple environmental cues may increase their dispersal capacity, and thus attract them from further away or enhance their flying foraging behaviour. Ladybirds' flight capacities were further increased when both MeSA and companion plants were positioned separately in the flight mill. This may have in situ applications: if ladybirds spend more time flying in response to spatial cues, they may have a greater probability of finding aphid populations in the field. Note that in the flight mill and in orchards, ladybirds may also have been attracted and stimulated by visual cues from companion plants; yellow flowers have been demonstrated to be particularly attractive to insects (Lunau \& Watch, 1994; Gumbert, 2000).

The wind-tunnel experiment provided insights on the contextual, short-distance foraging behaviour of $P$. japonica ladybirds. Although used in other ladybird species (Leroy et al., 2012), this design with three contiguous chambers and ladybirds being introduced at one end of the tunnel has some limitations regarding the statistical analysis because not all permutations of the three chambers were tested. However, the spatial separation versus the proximity of environmental cues (MeSA, companion plant and prey) affected ladybirds' foraging behaviour, and a symmetrical design with ladybirds introduced at equal distances from all tested cues would not have captured this result (Du et al., 1996; Dötterl et al., 2009).

MeSA was the most attractive cue in the windtunnel, but ladybirds most likely used it as a means to find prey because they later moved to the prey chamber or the plant chamber if no prey was present (Fig. 5). They therefore adjusted their foraging behaviour to the presence or absence of prey. We also showed that ladybirds used MeSA as a precise cue for the spatial location of prey: they found prey faster when the MeSA chamber was close to the prey chamber, and otherwise kept searching for prey close to MeSA dispensers. This finding is in agreement with the literature on HIPVs, used by herbivores' natural enemies to find plants hosting prey (Ode, 2006; Braasch et al., 2012; Gadino et al., 2012; Gençer et al., 2017; Turlings \& Erb, 2018). Aphids were the preferred food resource over floral resources, likely because of their higher nutritional value for ladybirds (Lundgren, 2009). Because aphids were not visible to ladybirds in the wind-tunnel, the specific foraging behaviour elicited by their presence was likely mediated 
by semiochemicals, such as the alarm pheromone (E)- $\beta$ farnesene. This semiochemical is produced by aphids in response to a danger, such as predators, and attracts predatory ladybirds into crop fields (Al Abassi et al., 2000; Francis et al., 2004); however it may not always be a short-distance attractant for ladybirds (Joachim et al., 2015). Compared with arthropods' semiochemicals that are mostly species-specific, more generalist HIPVs may result in a more sustained attraction of natural enemies and hence enhance pest management (Rodriguez-Saona \& Stelinski, 2009; Kaplan, 2012).

In our study, we did not quantify the impact of MeSA dispensers and companion plants application within orchards on non-targeted arthropods. Additional food resources from companion plants may also enhance pest populations (Wäckers et al., 2007; Parolin et al., 2012). Although A. citricola is among the most abundant pest in apple orchards in north China (Yin et al., 2013) and was efficiently regulated in our study, other minor pests in apple orchards may be differentially affected by the treatment, and even benefit from reduced competition by $A$. citricola in the long term. Outbreaks of non-target pests due to the regulation of major pests have been shown in other systems (Lu et al., 2012). In addition, the presence of synthetic HIPVs and companion plants may affect pollinators (Kearns \& Inouye, 1997) and nonentomophagous arthropod predators (Tabata et al., 2011) but also non-targeted natural enemies (Orre et al., 2010; Orre-Gordon et al., 2013). Therefore it will be important to measure to what extent the application of synthetic HIPVs and companion plants in apple orchards affect the arthropod community in an integrated pest management perspective.

Another aspect which will deserve further attention is the role of visual cues from $C$. officinalis as well as the number and concentration of MeSA dispensers, since it may affect the efficacy of different spatial arrangements in attracting targeted natural enemies (van Wijk et al., 2008; Kaplan \& Lewis, 2015). In our orchard experiment, the concentration of synthetic MeSA may have varied locally with microclimatic conditions. We minimized these differences as much as possible by placing them into partially buried boxes covered with a fine mesh to allow volatile diffusion, and similarly exposed to sun across orchards. MeSA concentration may have also varied temporally according with meteorological conditions, and this may have affected insects' population dynamics. However, the temporal variations were likely equivalent across orchards because they were in the same geographic area.

Conservation biological control, by managing ecosystem services, includes the consideration of functional habitat, the temporary application of specific companion plants and synthetic HIPVs to enhance the control of target pests and the overall biodiversity in agricultural systems (Gurr et al., 2017). Enhancing biodiversity to promote biocontrol services may be more complex in orchards than in open, homogenous crop fields (Gurr et al., 2015), and must be carefully investigated. Our study reports a significant improvement of the practical implementation of an attract-and-reward strategy combining synthetic MeSA and C. officinalis companion plants in apple orchards to suppress aphid populations. We showed the importance of the spatial arrangement of MeSA dispensers and companion plants for improved pest management. Future work is necessary to better disentangle the link between the spatial arrangement of synthetic HIPVs and rewards and insects' population dynamics in both organic and conventional orchards to understand the long-term consequences of this strategy on the local ecosystem.). Still our present study on the implementation of an attract-and-reward strategy provides useful information for optimizing integrated pest management on apple orchards.

\section{AUTHORS' CONTRIBUTIONS}

N.D. and S.W. designed the study; D.X., F.Z. and S.W. conducted the experiments; C.C.J., Q.X.X. and R.R. analysed the data; and C.C.J., D.X., Q.X.X., S.W. and N.D. wrote the manuscript. All authors approved the final version of this manuscript for publication.

\section{ACKNOWLEDGEMENTS}

We thank Jinlin Chen (Department of Zoology, University of Oxford) for her comments on an earlier version of the manuscript. The study was funded by the National Key Research and Development Program of China (2017YFD0201000), the Beijing Key Laboratory of Environment-Friendly Management on Fruit Disease and Pests in North China (BZ0432), the Beijing Science and Technology Program (D171100001617003), the Youth Scientific Research Funds of Beijing Academy of Agricultural and Forestry Sciences (QNJJ201725), and the International Joint Research Program of BAAFS (GJHZ2016).

\section{DATA ACCESSIBILITY}

Data available via the Dryad Digital Repository. https://doi.org/10.5061/dryad.dt1h407 (Jaworski et al. 2019).

\section{REFERENCES}

Al Abassi, S., Birkett, M. A., Pettersson, J., Pickett, J. A., Wadhams, L. J. \& Woodcock, C. M. (2000) Response of the seven-spot ladybird to an aphid alarm pheromone and an alarm pheromone inhibitor is mediated by paired olfactory cells. Journal of Chemical Ecology, 26, 1765-1771.

Ali, A., Desneux, N., Lu, Y, Wu, K. (2018) Key aphid natural enemies showing positive effects on wheat yield through biocontrol services in northern China. Agriculture, Ecosystems \& Environment 226, 1-9.

Ali, A., Desneux, N., Lu, Y. H., Liu, B., Wu, K. M. (2016). Characterization of the natural enemy community attacking cotton aphid in the Bt cotton 
ecosystem in northern China. Scientific Reports, 6, 24273.

Baggen, L., Gurr, G. \& Meats, A. (1999) Flowers in tritrophic systems: mechanisms allowing selective exploitation by insect natural enemies for conservation biological control. Entomologia Experimentalis et Applicata, 91, 155-161.

Balzan, M. V., Bocci, G., Moonen, A.-C. (2016) Utilisation of plant functional diversity in wildflower strips for the delivery of multiple agroecosystem services. Entomologia Experimentalis et Applicata, 158, 304-319.

Beane, K.A. \& Bugg, R.L. (1998) Natural and artificial shelter to enhance arthropod biological agents. In Pickett C. H. \& Bugg R. L. (Eds.), Enhancing biological control: Hhabitat management to promote natural enemies of agricultural pests, pp. 239-254. University of California Press.

Benjamini, Y. \& Hochberg, Y. (1995) Controlling the false discovery rate: A practical and powerful approach to multiple testing. Journal of the Royal Statistical Society. Series B (Methodological), 57, 289-300.

Braasch, J., Wimp, G. M. \& Kaplan, I. (2012) Testing for phytochemical synergism: arthropod community responses to induced plant volatile blends across crops. Journal of Chemical Ecology, 38, 12641275.

Bradley, C. A. \& Altizer, S. (2005) Parasites hinder monarch butterfly flight: implications for disease spread in migratory hosts. Ecology Letters, 8, 29300.

Brennan, E. B. (2016) Agronomy of strip intercropping broccoli with alyssum for biological control of aphids. Biological Control, 97, 109-119.

Brewer, M. J., Gordy, J. W., Kerns, D. L., Woolley, J. B., Rooney, W. L. \& Bowling, R. D. (2017) Sugarcane aphid population growth, plant injury, and natural enemies on selected grain sorghum hybrids in Texas and Louisiana. Journal of Economic Entomology, 110, 2109-2118.

Bugg, R. L. \& Waddington, C. (1994) Using cover crops to manage arthropod pests of orchards: A review. Agriculture, Ecosystems \& Environment, 50, 1128.

Davison, A. \& Ricard, I. (2011) Comparison of models for olfactometer data. Journal of Agricultural, Biological, and Environmental Statistics, 16, 157169.

De Boer, J. G. \& Dicke, M. (2004) The role of methyl salicylate in prey searching behavior of the predatory mite Phytoseiulus persimilis. Journal of Chemical Ecology, 30, 255-271.

Delaney, K. J., Wawrzyniak, M., Lema’nczyk, G., Wrzesi'nska, D., Piesik, D. (2013) Synthetic cisjasmone exposure induces wheat and barley volatiles that repel the pest cereal leaf beetle, Oulema melanopus L. Journal of Chemical Ecology, 39, 620-629.
Dötterl, S., Jürgens, A., Wolfe, L. \& Biere, A. (2009) Disease status and population origin effects on floral scent: potential consequences for oviposition and fruit predation in a complex interaction between a plant, fungus, and noctuid moth. Journal of Chemical Ecology, 35, 307-319.

Du, Y. J., Poppy, G. M. \& Powell, W. (1996) Relative importance of semiochemicals from first and second trophic levels in host foraging behavior of Aphidius ervi. Journal of Chemical Ecology, 22, 1591-1605.

Fiedler, A. K., Landis, D. A. \& Wratten, S. D. (2008) Maximizing ecosystem services from conservation biological control: The role of habitat management. Biological Control, 45, 254-271.

Francis, F., Lognay, G. \& Haubruge, E. (2004) Olfactory responses to aphid and host plant volatile releases: (E)-Beta-farnesene an affective kairomone for the predator Adalia bipunctata. Journal of Chemical Ecology, 30, 741-755.

Gadino, A. N., Walton, V. M. \& Lee, J. C. (2012) Evaluation of methyl salicylate lures on populations of Typhlodromus pyri (Acari: Phytoseiidae) and other natural enemies in western Oregon vineyards. Biological Control, 63, 48-55.

Gençer, N. S., Kumral, N. A., Seidi, M. \& Pehlevan, B. (2017) Attraction responses of ladybird beetle Hippodamia variegata (Goeze, 1777) (Coleoptera: Coccinellidae) to single and binary mixture of synthetic herbivore-induced plant volatiles in laboratory tests. Turkish Journal of Entomology, 41, 17-26.

Gontijo, L. M.; Beers, E. H. \& Snyder, W. E. (2013) Flowers promote aphid suppression in apple orchards. Biological Control, 66, 8-15.

Gumbert, A. (2000) Color choices by bumble bees (Bombus terrestris): innate preferences and generalization after learning. Behavioral Ecology and Sociobiology, 48, 36-43.

Gurr, G. M.; Wratten, S. D.; Landis, D. A. \& You, M. (2017) Habitat management to suppress pest populations: progress and prospects. Annual Review of Entomology, 62, 91-109.

Gurr, G. M., Lu, Z., Zheng, X., Xu, H., Zhu, P., Chen, G., ... Heong, K. L. (2015) Multi-country evidence that crop diversification promotes ecological intensification of agriculture. Nature Plants, 2, 16014.

Huang, N., Enkegaard, A., Osborne, L. S., Ramakers, P. M. J., Messelink, G. J., Pijnakker, J. \& Murphy, G. (2011) The banker plant method in biological control. Critical Reviews in Plant Sciences, 30, 259-278.

James, D. G. (2003) Field evaluation of herbivoreinduced plant volatiles as attractants for beneficial insects: methyl salicylate and the green lacewing, Chrysopa nigricornis. Journal of Chemical Ecology, 29, 1601-1609.

Jaworski C, Xiao D, Xu Q, Ramirez-Romero R, Guo X, Wang S, Desneux N. Data from: Varying the 
spatial arrangement of synthetic herbivore-induced plant volatiles and companion plants to improve conservation biological control. Dryad Digital Repository. https://doi.org/10.5061/dryad.dt1h407.

Joachim, C., Vosteen, I. \& Weisser, W. W. (2015) The aphid alarm pheromone (E)- $\beta$-farnesene does not act as a cue for predators searching on a plant. Chemoecology, 25, 105-113.

Jonsson, M., Wratten, S. D., Landis, D. A., Gurr, G. M. (2008) Recent advances in conservation biological control of arthropods by arthropods. Biological Control, 45, 172-175.

Kaplan, I. \& Lewis, D. (2015) What happens when crops are turned on? Simulating constitutive volatiles for tritrophic pest suppression across an agricultural landscape. Pest Management Science, 71, 139-150.

Kaplan, I. (2012) Attracting carnivorous arthropods with plant volatiles: The future of biocontrol or playing with fire?. Biological Control, 60, 77-89.

Karp, D. S., Chaplin-Kramer, R., Meehan, T. D., Martin, E. A., DeClerck, F., Grab, H. ... Zou, Y. (2018) Crop pests and predators exhibit inconsistent responses to surrounding landscape composition. Proceedings of the National Academy of Sciences, 115, E7863-E7870.

Kean, J., Wratten, S., Tylianakis, J. \& Barlow, N. (2003) The population consequences of natural enemy enhancement, and implications for conservation biological control. Ecology Letters, 6, 604-612.

Kearns, C. A. \& Inouye, D. W. (1997) Pollinators, flowering plants, and conservation biology. BioScience, 47, 297-307.

Kremen, C. (2005) Managing ecosystem services: what do we need to know about their ecology?. Ecology Letters, 8, 468-479.

Landis, D. A., Wratten, S. D. \& Gurr, G. M. (2000) Habitat management to conserve natural enemies of arthropod pests in agriculture. Annual Review of Entomology, 45, 175-201.

Leroy, P. D., Schillings, T., Farmakidis, J., Heuskin, S., Lognay, G., Verheggen, F. J., Brostaux, Y., Haubruge, E. \& Francis, F. (2012) Testing semiochemicals from aphid, plant and conspecific: attraction of Harmonia axyridis. Insect Science, 19, 372-382.

Li, S., Tan, X., Desneux, N., Benelli, G., Zhao, J., Li, X., Zhang, F., Gao, X. \& Wang, S. (2015) Innate positive chemotaxis to pollen from crops and banker plants in predaceous biological control agents: towards new field lures?. Scientific Reports, 5, 12729.

Louda, S. M., Pemberton, R. W., Johnson, M. T. \& Follett, P. A. (2003) Non-target effects - the Achilles' heel of biological control? Retrospective analyses to reduce risk associated with biocontrol introductions. Annual Review of Entomology, 48, 365-396.

Lu, Y. H., Wu, K. M., Jiang, Y. Y., Guo, Y. Y. \& Desneux, N. (2012). Widespread adoption of Bt cotton and insecticide decrease promotes biocontrol services. Nature, 487, 362-365.

Lucchi, A., Loni, A., Gandini, L. M., Scaramozzino, P., Ioriatti, C., Ricciardi, R. \& Schearer, P. W. (2017). Using herbivore-induced plant volatiles to attract lacewings, hoverflies and parasitoid wasps in vineyards: achievements and constraints. Bulletin of Insectology, 70, 273-282.

Lunau, K. \& S. Wacht. (1994) Optical releasers of innate proboscis extension in the hoverfly Eristalis tenax L. (Diptera: Syrphidae). Journal of Comparative Physiology, 174, 575-579.

Lundgren, J. G. (2009) Nutritional aspects of non-prey foods in the life histories of predaceous Coccinellidae. Biological Control, 51, 294-305.

Maes, S., Massart, X., Grégoire, J.-C. \& De Clercq, P. (2014) Dispersal potential of native and exotic predatory ladybirds as measured by a computermonitored flight mill. BioControl, 59, 415-425.

Martínez-Uña, A., Martín, J. M., Fernández-Quintanilla, C. \& Dorado, J. (2013) Provisioning floral resources to attract aphidophagous hoverflies (Diptera: Syrphidae) useful for pest management in central Spain. Journal of Economic Entomology, 106, 2327-2335.

Michaud, J. (2018) Challenges to conservation biological control on the High Plains: 150 years of evolutionary rescue. Biological Control, 125, 6573.

Nemec, K.; Beckendorf, E.; Hesler, L.; Riedell, W. \& Lundgren, J. (2016) The effect of flowering calendula and cuphea plants on Orius insidiosus survival and predation of Aphis glycines. Biocontrol Science and Technology, 26, 12-22.

Ninkovic, V. \& Pettersson, J. (2003) Searching behaviour of the sevenspotted ladybird, Coccinella septempunctata - effects of plant-plant odour interaction. Oikos, 100, 65-70.

Ode, P. J. (2006) Plant chemistry and natural enemy fitness: effects on herbivore and natural enemy interactions. Annual Review of Entomology, 51, 163-185.

Orre-Gordon, G. U. S., Wratten, S. D., Jonsson, M., Hale, R., Simpson, M. (2013) 'Attract and reward': Effects of combining a herbivore induced plant volatile with floral resource supplementation on arthropods from three trophic levels. Biological Control 64, 106-115.

Orre, G. U. S., Wratten, S. D., M. Jonsson, M., Hale, R. J. (2010) Effects of an herbivore-induced plant volatile on arthropods from three trophic levels in brassicas. Biological Control 53, 62-67.

Parolin, P., Bresch, C., Desneux, N., Brun, R., Bout, A., Boll, R. \& Poncet, C. (2012) Secondary plants used in biological control: A review. International Journal of Pest Management, 58, 91-100.

Perović, D. J.; Gámez-Virués, S.; Landis, D. A.; Wäckers, F.; Gurr, G. M.; Wratten, S. D.; You, M.-S. \& Desneux, N. (2018) Managing biological control 
services through multi-trophic trait interactions: review and guidelines for implementation at local and landscape scales. Biological Reviews, 93, 306321.

Petterson, J., Picket, J. A., Pye, B. J., Quiroz, A., Smart, L. E., Wadhams, L. J., Woodcock, C. M. (1994) Winter host component reduces colonization by bird-cherry-oat aphid, Rhopalosiphum padi (L.) (Homoptera, Aphididae), and other aphids in cereal fields. Journal of Chemical Ecology, 20, 25652574.

Qi, L., Jiang, L.-R., Qin, H.-G., Han, N. B.-Y. \& Wang, R.-F. (2008) Behaviour responses of Propylaea japonica to volatiles from tea plants. Acta Agricultural Zhejiangensis.

R Core Team (2015) R: A Language and Environment for Statistical Computing.

Ribak, G., Barkan, S. \& Soroker, V. (2017) The aerodynamics of flight in an insect flight-mill. PloS ONE, 12, 1-25.

Ricard, I. \& Davison, A. C. (2007) Statistical inference for olfactometer data. Journal of the Royal Statistical Society. Series C (Applied Statistics), 56, 479-492.

Ricci, C., Ponti, L. \& Pires, A. (2005) Migratory flight and pre-diapause feeding of Coccinella septempunctata (Coleoptera) adults in agricultural and mountain ecosystems of central Italy. European Journal of Entomology, 102, 531-538.

Ricciardi, A. \& Simberloff, D. (2009) Assisted colonization is not a viable conservation strategy. Trends in Ecology \& Evolution, 24, 248-253.

Rodriguez-Saona, C., Kaplan, I., Braasch, J., Chinnasamy, D. \& Williams, L. (2011) Field responses of predaceous arthropods to methyl salicylate: A meta-analysis and case study in cranberries. Biological Control, 59, 294-303.

Rodriguez-Saona, C. R. \& Stelinski, L. L. (2009) Behavior-Modifying Strategies in IPM: Theory and Practice, Chapter 11. In Peshin, R. \& Dhawan, A. K. (Eds.) Integrated Pest Management: Innovation-Development Process. Springer, pp. 261-312.

Rouyar, A., Deisig, N., Dupuy, F., Limousin, D., Wycke, M.-A., Renou, M. \& Anton, S. (2015) Unexpected plant odor responses in a moth pheromone system. Frontiers in Physiology, 6, 148.

Salamanca, J., Souza, B. \& Rodriguez-Saona, C. (2018) Cascading effects of combining synthetic herbivore-induced plant volatiles with companion plants to manipulate natural enemies in an agroecosystem. Pest Management Science, 74, 21332145.

Salom, S. M. \& McLean, J. A. (1991) Flight behavior of scolytid beetle in response to semiochemicals at different wind speeds. Journal of Chemical Ecology, 17, 647-661.

Simberloff, D. \& Stiling, P. (1996) How risky is biological control?. Ecology, 77, 1965-1974.
Simpson, M., Gurr, G. M., Simmons, A. T., Wratten, S. D., James, D. G., Leeson, G., Nicol, H. I. \& OrreGordon, G. U. S. (2011a) Attract and reward: combining chemical ecology and habitat manipulation to enhance biological control in field crops. Journal of Applied Ecology, 48, 580-590. .

Simpson, M., Gurr, G., Simmons, A., Wratten, S., James, D., Leeson, G., Nicol, H. \& Orre, G. (2011b) Field evaluation of the 'attract and reward' biological control approach in vineyards. Annals of Applied Biology, 159, 69-78.

Soler, R., Badenes-Pérez, F. R., Broekgaarden, C., Zheng, S.-J., David, A., Boland, W., Dicke, M. (2012) Plant-mediated facilitation between a leaf-feeding and a phloem-feeding insect in a brassicaceous plant: from insect performance to gene transcription. Functional Ecology, 26, 156-166.

Stephens, M. J., France, C. M., Wratten, S. D. \& Frampton, C. (1998) Enhancing biological control of leafrollers (Lepidoptera: Tortricidae) by sowing buckwheat (Fagopyrum esculentum) in an orchard. Biocontrol Science and Technology, 8, 547-558.

Tabata, J., De Moraes, C. M. \& Mescher, M. C. (2011) Olfactory cues from plants infected by powdery mildew guide foraging by a mycophagous ladybird beetle. PLoS ONE, 6, 1-6.

Taylor, R. A. J., Bauer, L. S., Poland, T. M. \& Windell, K. N. (2010) Flight performance of Agrilus planipennis (Coleoptera: Buprestidae) on a flight mill and in free flight. Journal of Insect Behavior, 23, 128-148.

Turlings, T. C. \& Erb, M. (2018) Tritrophic interactions mediated by Herbivore-Induced Plant Volatiles: mechanisms, ecological relevance, and application potential. Annual Review of Entomology, 63, 433452.

Tschumi, M., Albrecht, M., Collatz, J., Dubsky, V., Entling, M. H., Najar-Rodriguez, A. J. \& Jacot, K. (2016) Tailored flower strips promote natural enemy biodiversity and pest control in potato crops. Journal of Applied Ecology, 53, 1169-1176.

Vandereycken, A., Durieux, D., Joie, E., Sloggett, J. J.., Haubruge, E., Verheggen, F. J. (2013) Is the multicolored Asian ladybeetle, Harmonia axyridis, the most abundant natural enemy to aphids in agroecosystems? Journal of Insect Science, 13, 158.

Vet, L. E. M. \& Dicke, M. (1992) Ecology of infochemical use by natural enemies in a tritrophiccontext. Annual Review of Entomology, 37, 141-172.Wang, S., Michaud, J. P., Tan, X. L., Zhang, F. \& Guo, X. J. (2011) The aggregation behavior of Harmonia axyridis in its native range in Northeast China. BioControl, 56, 193-206.

Vet, L. E. M., Van Lenteren, J. C., Heymans, M. \& Meelis, E. (1983) An airflow olfactometer for measuring olfactory responses of hymenopterous parasitoids and other small insects. Physiological Entomology, 8, 97-106. 
Wäckers, F. L., Romeis, J., van Rijn, P. (2007) Nectar and pollen feeding by insect herbivores and implications for multitrophic interactions. Annual Review of Entomology, 52, 301-323.

Wang, S., Michaud, J. P., Tan, X. L., Zhang, F., Guo, X. J. (2011) The aggregation behavior of Harmonia axyridis in its native range in Northeast China. BioControl, 56, 193-206.

van Wijk, M., De Bruijn, P. J. A., Sabelis, M. W. (2008) Predatory mite attraction to herbivore-induced plant odors is not a consequence of attraction to individual herbivore-induced plant volatiles. Journal of Chemical Ecology, 34, 791.

Wu, K. \& Guo, Y. (2005) The evolution of cotton pest management practices in China. Annual Review of Entomology, 50, 31-52.
Yin, W. D., Qiu, G. S., Yan, W. T., Sun, L. N., Zhang, H. J. (2013) Host preference and fitness of Aphis citricola (Hemiptera: Aphidididae) to mature and young apple leaves. Chinese Journal of Applied Ecology, 23, 2000-2006.

Zhao, J., Guo, X., Tan, X., Desneux, N., Zappala, L., Zhang, F. \& Wang, S. (2017) Using Calendula officinalis as a floral resource to enhance aphid and thrips suppression by the flower bug Orius sauteri (Hemiptera: Anthocoridae). Pest Management Science, 73, 515-520.

Zhu, J. \& Park, K.-C. (2005) Methyl salicylate, a soybean aphid-induced plant volatile attractive to the predator Coccinella septempunctata. Journal of Chemical Ecology, 31, 1733-1746. 


\section{Supporting Information}

Varying the spatial arrangement of synthetic herbivore-induced plant volatiles and companion plants to improve conservation biological control

Coline C. JAWORSKI, Da XIAO, Qingxuan XU, Ricardo RAMIREZ-ROMERO, Xiaojun GUO, Su WANG, Nicolas DESNEUX

\section{A. Laboratory experiment: impact of marigold complement in $P$. japonica diet}

Newly emerged $P$. japonica adults were placed individually in a cage and provided with 100 third instar nymphs of Myzus persicae aphids and one potted plant of C. officinalis with exactly three open flowers. Aphids and potted plants were renewed daily. A first group of virgin females was used to assess the influence of flowers on longevity $(\mathrm{N}=45)$, and a second group was used to assess fecundity. Males were removed after copulation and newly deposited eggs by females were counted daily during ten days $(\mathrm{N}=45)$.

Flower supplementation had a significant positive impact on female longevity (Fig. $\mathrm{S} 1 ; \mathrm{t}$-test; $\mathrm{t}=$ 9.2798; $\mathrm{df}=84.993 ; P<0.001$; Shapiro test for normality: $\mathrm{W}=0.98804 ; P=0.59$ ) and fecundity $(t$-test; $\mathrm{t}=-6.9757 ; \mathrm{df}=70.842 ; P<0.001$; Shapiro test for normality: $\mathrm{W}=0.96674 ; P=0.021$ ).
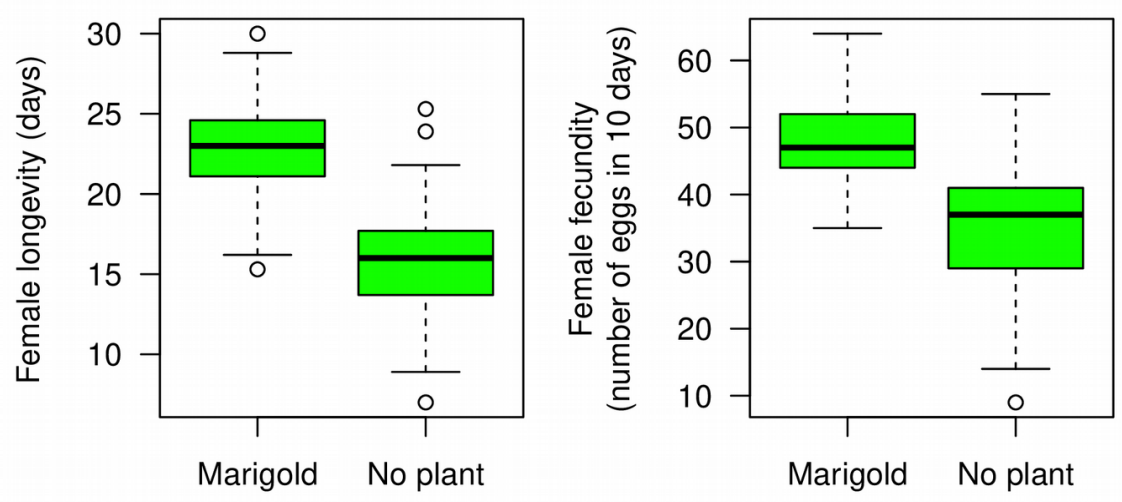

Fig. S1. Longevity (left) and fecundity (right) of P. japonica females fed with Myzus persicae alone or in addition to flowering $C$. officinalis plants $(\mathrm{N}=45)$.

\section{B. Preliminary orchard experiments}

Methods - Additional information (please refer to main text for further details)

In 2013 and 2014, we treated orchards with either companion plants alone or MeSA dispensers alone inside blocks of trees in the nine orchards described in the main text. The treatments (control / application of potted companion plants only / application of MeSA dispensers only) were randomized within the nine orchards across years, with three orchards per treatment.

In 2015, we treated Orchard \#1 (Fig. S4) with companion plants and MeSA dispensers placed together (10 cm apart) inside the central block of trees, while Orchard \#9 was used as a control.

Numbers of ladybirds and of aphids per branch in 2013-2014 were analysed separately using a GLMM with a negative binomial distribution. The fixed effects were the treatment, the year and the interaction between the two and the random effects were the tree number nested within the orchard number. However, random effects were estimated to zero and were thus removed for both ladybird and aphid models. Since the treatment significantly affected population dynamics, 
multiple comparisons of means were performed by Tukey's HSD (function 'glht' from R library 'multcomp'). We analysed the differences in numbers of ladybirds and of aphids between treatments in 2015 using Kruskal-Wallis tests.

\section{Results}

The treatment in interaction with the year had a marginal effect on the numbers of ladybirds per branch of target apple trees in 2013 and 2014 when companion plants and MeSA dispensers were applied separately (Fig. S2A,B; $x^{2}=6.96, \mathrm{df}=2, P=0.031$ ), with ladybird numbers $22 \%$ higher in MeSA-only treated orchards relative to control orchards (Table S1). Ladybird numbers in companion plant-only treated orchards were not different from either those in control orchards nor in MeSA-only treated orchards. Similarly, numbers of aphids per branch were affected by the treatment in interaction with the year (Fig. S1C,D; $X^{2}=10.57, \mathrm{df}=2, P=0.0051$ ). Numbers of aphids were $27 \%$ and $16 \%$ lower in MeSA-only and companion plant-only treated orchards, respectively, relative to control orchards (Table S1).

In 2015, when both MeSA dispensers and companion plants were placed together in the orchard, numbers of ladybirds (Fig. S3A; KW-Chi $=0.1934$; $\mathrm{df}=1 ; P=0.66$ ) and of aphids per branch (Fig. S3B; KW-Chi ${ }^{2}=0.33041 ; \mathrm{df}=1 ; P=0.56$ ) were not different from that of the control orchard. Because we were interested in improving an attract-and-reward strategy to efficiently control aphids in apple orchards, we did not replicate this clustered spatial arrangement but instead we tested the effect of spatially separating synthetic HIPVs and rewards in orchards in 2016 (main text).

Table S1. Tukey contrasts and $P$-values (in parentheses) on the number of ladybirds and of aphids per branch of target apple tree (glm with a negative binomial distribution) between treatments.

\begin{tabular}{lcc}
\hline & $\begin{array}{c}\text { Companion } \\
\text { plants }\end{array}$ & MeSA \\
\hline$\underline{\text { Ladybirds }}$ & & $-0.14(0.0056)$ \\
Control & $-0.036(0.70)$ & $-0.10(0.056)$ \\
Companion plants & & \\
$\underline{\text { Aphids }}$ & & $0.26(<0.001)$ \\
Control & $0.14(<0.001)$ & $0.12(<0.001)$ \\
\hline
\end{tabular}




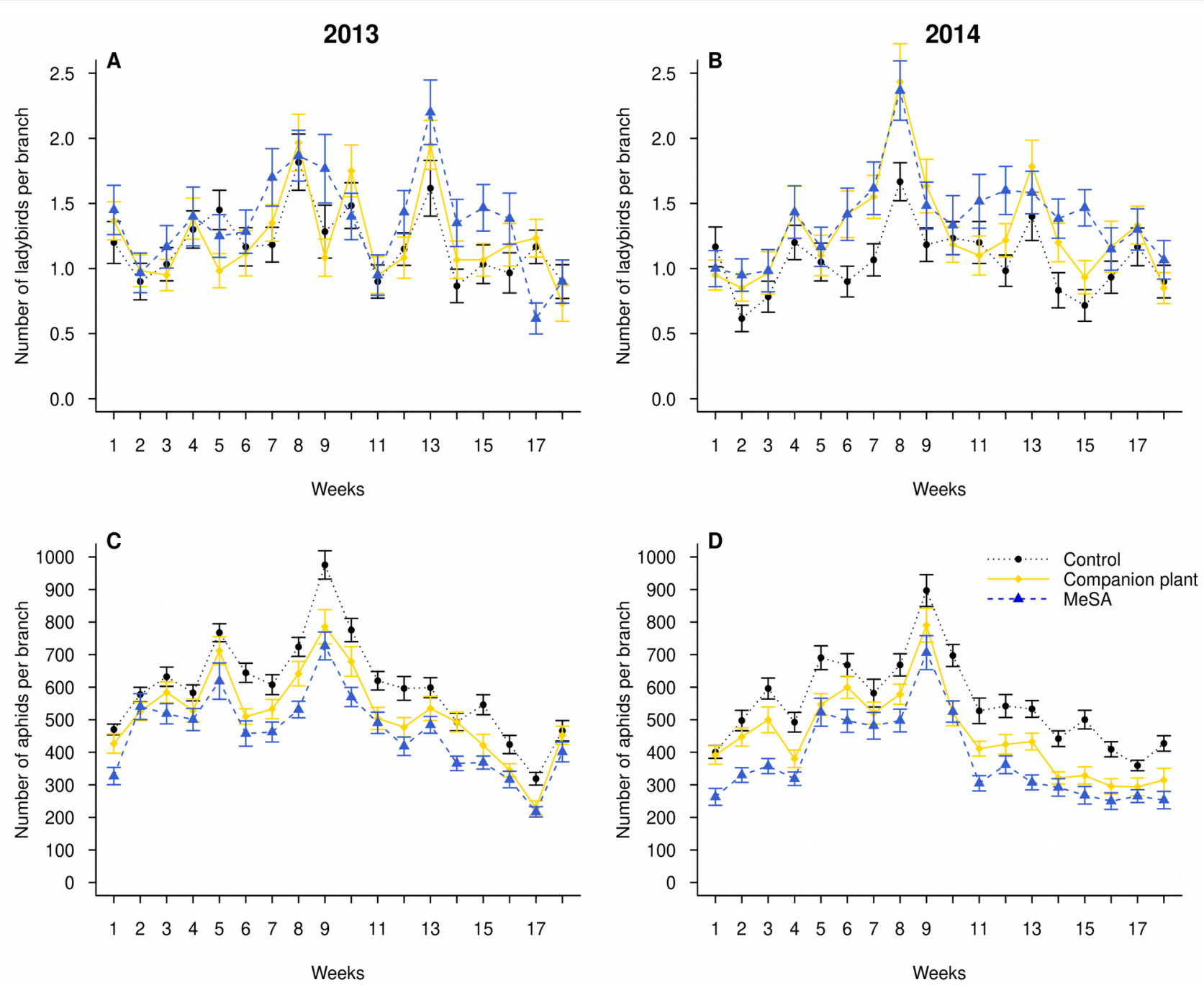

Fig. S2. Mean number ( \pm SE) of ladybirds (A, B) and aphids (C, D) per branch of target apple tree in 2013 and 2014 in control orchards and orchards treated with MeSA dispensers alone or companion plants alone. $\mathrm{N}=60$ (three orchards per treatment; five trees per orchard; four branches per tree).
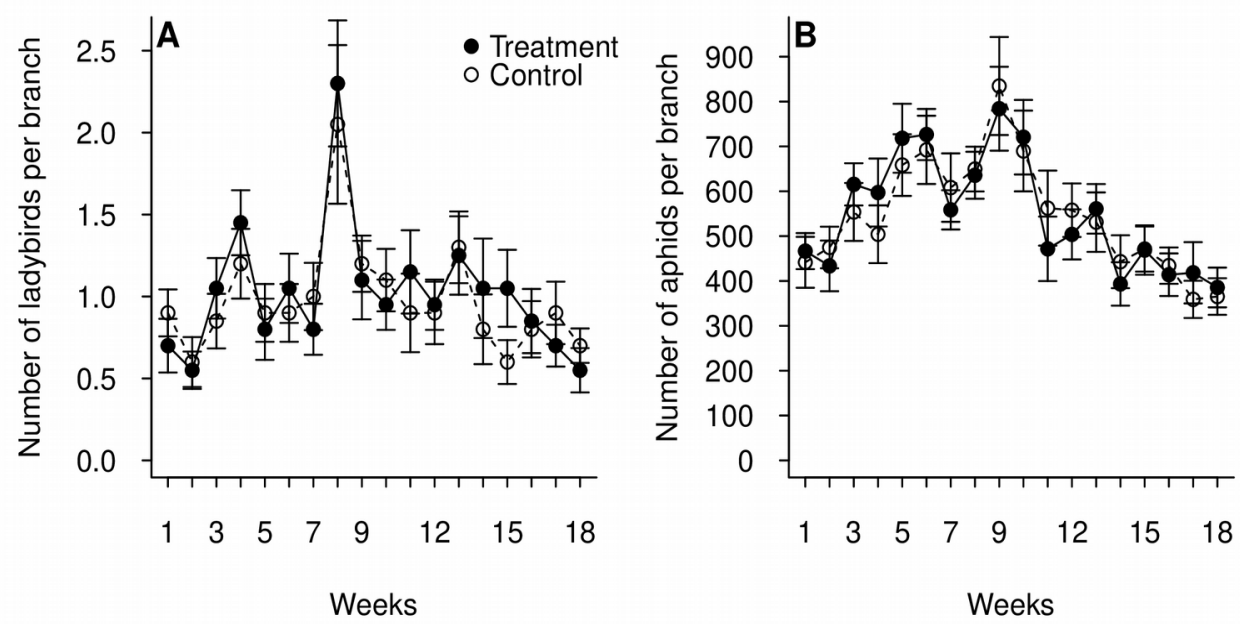

Fig. S3. Mean number $( \pm S E)$ of ladybirds $(A)$ and aphids $(B)$ per branch of target apple tree in 2015 in a control orchard and an orchard treated with MeSA dispensers and companion plants placed together. $\mathrm{N}=20$ (five trees per orchard; four branches per tree). 


\section{Supplementary Material for the main study}

Table S2. Coordinates of the nine orchards.

\begin{tabular}{|c|c|c|}
\hline Number & Location & Coordinates \\
\hline \#1 & Wang-Jia-Yuan & N 4010'44.44"; E 116²'41.90" \\
\hline \#2 & Bei-Liu & N 4011'7.09"; E 116³'14.02" \\
\hline \#3 & Sheng-Qiang & N 4011'10.57"; E 116³'38.75" \\
\hline \#4 & Xin-Liu & N 4010'54.41"; E 116²'49.28" \\
\hline \#5 & Nan-Liu & N 4010'40.89"; E 116³'26.00" \\
\hline \#6 & Feng-Sheng & N 4011'5.82"; E 116² $4^{\prime} 9.08^{\prime \prime}$ \\
\hline \#7 & Gong-Qin & N 4011'42.78"; E $116^{\circ} 2^{\prime} 3.56^{\prime \prime}$ \\
\hline \#8 & Nan-Kou & N 4010'16.26"; E 116²'19.46" \\
\hline$\# 9$ & Luo-Luo & N 4010'37.98"; E 116²'32.97" \\
\hline
\end{tabular}

Table S3. Tukey contrasts and $P$-values (in parentheses) on the number of ladybirds per four branches of apple tree (glm with a negative binomial distribution; Table 1) between treatments in orchards.

\begin{tabular}{lcc}
\hline & T2 & Control \\
\hline$\underline{\text { Short-term }}$ & & \\
Ladybirds & & \\
T1 & $0.43(<0.001)$ & $1.53(<0.001)$ \\
T2 & & $1.10(<0.001)$ \\
Aphids & & \\
T1 & $-0.60(<0.001)$ & $-1.26(<0.001)$ \\
T2 & & $-0.66(<0.001)$ \\
& & \\
Long-term & & \\
Ladybirds & & $-0.74(<0.001)$ \\
T1 & $-0.83(<0.001)$ & $0.083(0.15)$ \\
T2 & & \\
Aphids & & $-3.29(<0.001)$ \\
T1 & $-1.05(<0.001)$ & $-2.24(<0.001)$ \\
T2 & &
\end{tabular}

Table S4. Tukey mean difference (first row) and $P$-values (second row) in yields between treatments in orchards.

\begin{tabular}{lcc}
\hline & T1 & T2 \\
\hline T2 & 234.9 & \\
& 0.0060 & \\
\hline Control & 484.4 & 249.5 \\
& 0.00012 & 0.0044 \\
\hline
\end{tabular}


Jaworski et al. - Varying the spatial arrangement of synthetic herbivore-induced plant volatiles and companion plants to improve conservation biological control

Table S5. Tukey mean difference (first row) and $P$-values (second row) on total flight distance (m) between treatments in the flight mill experiment.

\begin{tabular}{|c|c|c|c|c|}
\hline & Control & $\begin{array}{c}\text { Two companion } \\
\text { plants }\end{array}$ & $\begin{array}{l}\text { Two MeSA } \\
\text { dispensers }\end{array}$ & $\begin{array}{l}\text { One companion plant and one } \\
\text { MeSA dispenser together }\end{array}$ \\
\hline Two companion plants & $\begin{array}{c}4442 \\
0.043 *\end{array}$ & & & \\
\hline Two MeSA dispensers & $\begin{array}{c}4698 \\
0.028 *\end{array}$ & $\begin{array}{l}256 \\
0.99\end{array}$ & & \\
\hline $\begin{array}{l}\text { One companion plant and one } \\
\text { MeSA dispenser together }\end{array}$ & $\begin{array}{c}11122 \\
<0.001 * * *\end{array}$ & $\begin{array}{c}6681 \\
<0.001 * * *\end{array}$ & $\begin{array}{c}6425 \\
<0.001 * * *\end{array}$ & \\
\hline $\begin{array}{l}\text { One companion plant and one } \\
\text { MeSA dispenser separately }\end{array}$ & $\begin{array}{c}16512 \\
<0.001 * * *\end{array}$ & $\begin{array}{c}12071 \\
<0.001 * * *\end{array}$ & $\begin{array}{c}11815 \\
<0.001 * * *\end{array}$ & $\begin{array}{c}5390 \\
0.0074 * *\end{array}$ \\
\hline
\end{tabular}

Table S6. Tukey mean difference (first row) and $P$-values (second row) on total flight duration (min) between treatments in the flight mill experiment.

\begin{tabular}{|c|c|c|c|c|}
\hline & Control & $\begin{array}{l}\text { Two companion } \\
\text { plants }\end{array}$ & $\begin{array}{l}\text { Two MeSA } \\
\text { dispensers }\end{array}$ & $\begin{array}{l}\text { One companion plant and one } \\
\text { MeSA dispenser together }\end{array}$ \\
\hline Two companion plants & $\begin{array}{c}68.24 \\
0.035 *\end{array}$ & & & \\
\hline Two MeSA dispensers & $\begin{array}{c}69.60 \\
0.030 *\end{array}$ & $\begin{array}{l}1.35 \\
0.99\end{array}$ & & \\
\hline $\begin{array}{l}\text { One companion plant and one } \\
\text { MeSA dispenser together }\end{array}$ & $\begin{array}{c}105.63 \\
<0.001 * * *\end{array}$ & $\begin{array}{c}37.39 \\
0.50\end{array}$ & $\begin{array}{c}36.04 \\
0.54\end{array}$ & \\
\hline $\begin{array}{l}\text { One companion plant and one } \\
\text { MeSA dispenser separately }\end{array}$ & $\begin{array}{c}123.95 \\
<0.001 * * *\end{array}$ & $\begin{array}{c}55.71 \\
0.13\end{array}$ & $\begin{array}{c}54.35 \\
0.15\end{array}$ & $\begin{array}{c}18.31 \\
0.93\end{array}$ \\
\hline
\end{tabular}

'*': $P<0.5$; '***': $P<0.001$.

Table S7. Tukey mean difference (first row) and $P$-values (second row) on square-root transformed average speed $\left(\mathrm{m}^{1 / 2} \cdot \mathrm{min}^{-1 / 2}\right)$ between treatments in the flight mill experiment.

\begin{tabular}{|c|c|c|c|c|}
\hline & Control & $\begin{array}{c}\text { Two companion } \\
\text { plants }\end{array}$ & $\begin{array}{l}\text { Two MeSA } \\
\text { dispensers }\end{array}$ & $\begin{array}{l}\text { One companion plant and one } \\
\text { MeSA dispenser together }\end{array}$ \\
\hline Two companion plants & $\begin{array}{l}0.31 \\
0.98\end{array}$ & & & \\
\hline Two MeSA dispensers & $\begin{array}{l}0.21 \\
0.99\end{array}$ & $\begin{array}{c}-0.097 \\
0.99\end{array}$ & & \\
\hline $\begin{array}{l}\text { One companion plant and one } \\
\text { MeSA dispenser together }\end{array}$ & $\begin{array}{l}1.10 \\
0.22\end{array}$ & $\begin{array}{l}0.79 \\
0.54\end{array}$ & $\begin{array}{l}0.89 \\
0.43\end{array}$ & \\
\hline $\begin{array}{l}\text { One companion plant and one } \\
\text { MeSA dispenser separately }\end{array}$ & $\begin{array}{c}1.76 \\
0.0084^{* *}\end{array}$ & $\begin{array}{c}1.45 \\
0.047 *\end{array}$ & $\begin{array}{c}1.55 \\
0.028 *\end{array}$ & $\begin{array}{l}0.66 \\
0.71\end{array}$ \\
\hline
\end{tabular}

'*': $P<0.5$; '**': $P<0.01$. 
Table S8. Wald test $P$-values on pairwise comparisons of proportions of ladybirds attracted by the four different olfactory stimuli in the olfactometer test.

\begin{tabular}{lccc}
\hline & Control & MeSA dispenser & Companion plant \\
MeSA dispenser & $<0.001$ & & \\
Companion plant & $<0.001$ & $<0.001$ & \\
\hline $\begin{array}{l}\text { MeSA dispenser }+ \\
\text { companion plant }\end{array}$ & $<0.001$ & $<0.001$ & $<0.001$ \\
\hline
\end{tabular}

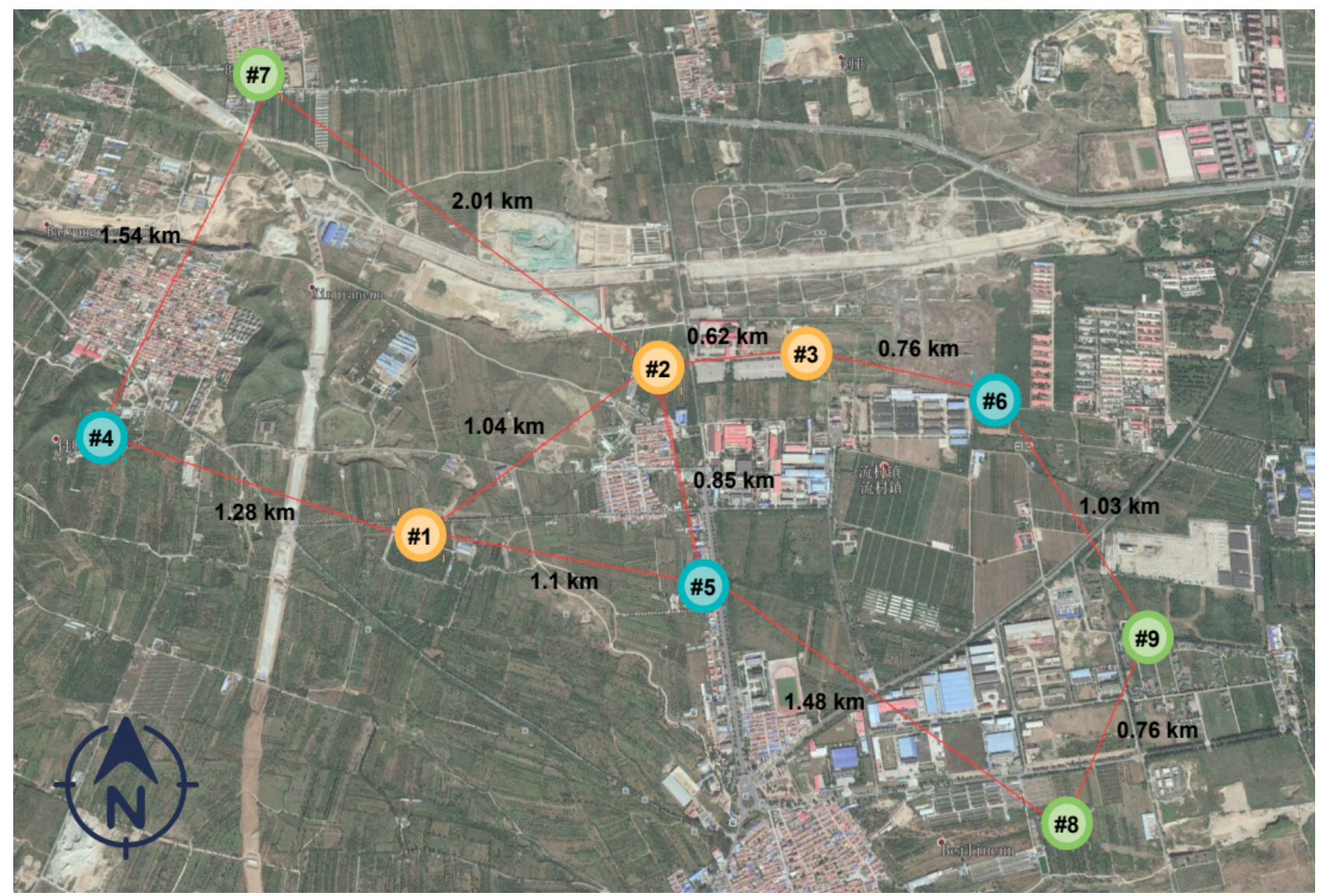

Fig. S4. Map of the nine orchards. 


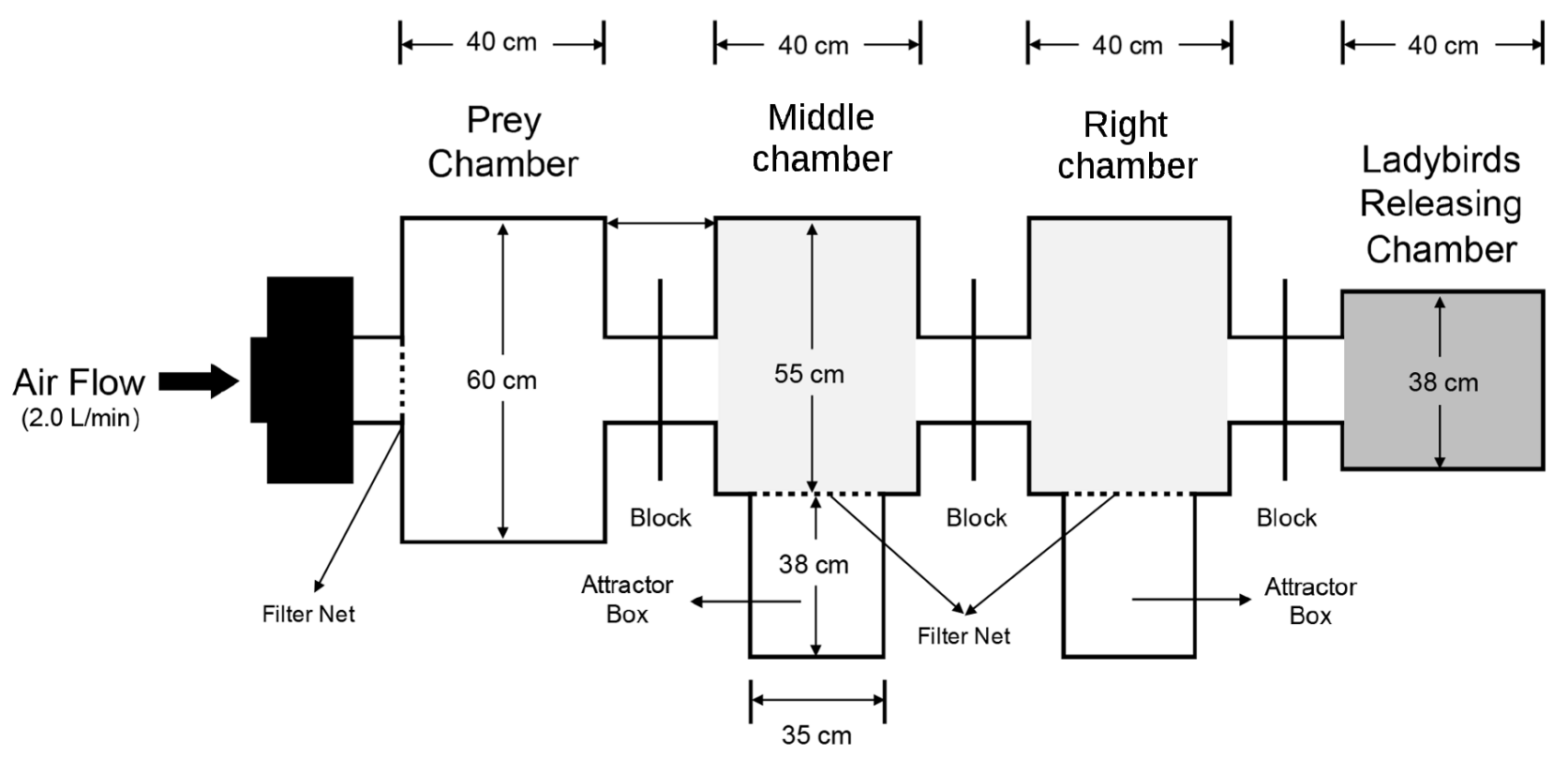

Fig. S5. Wind-tunnel.

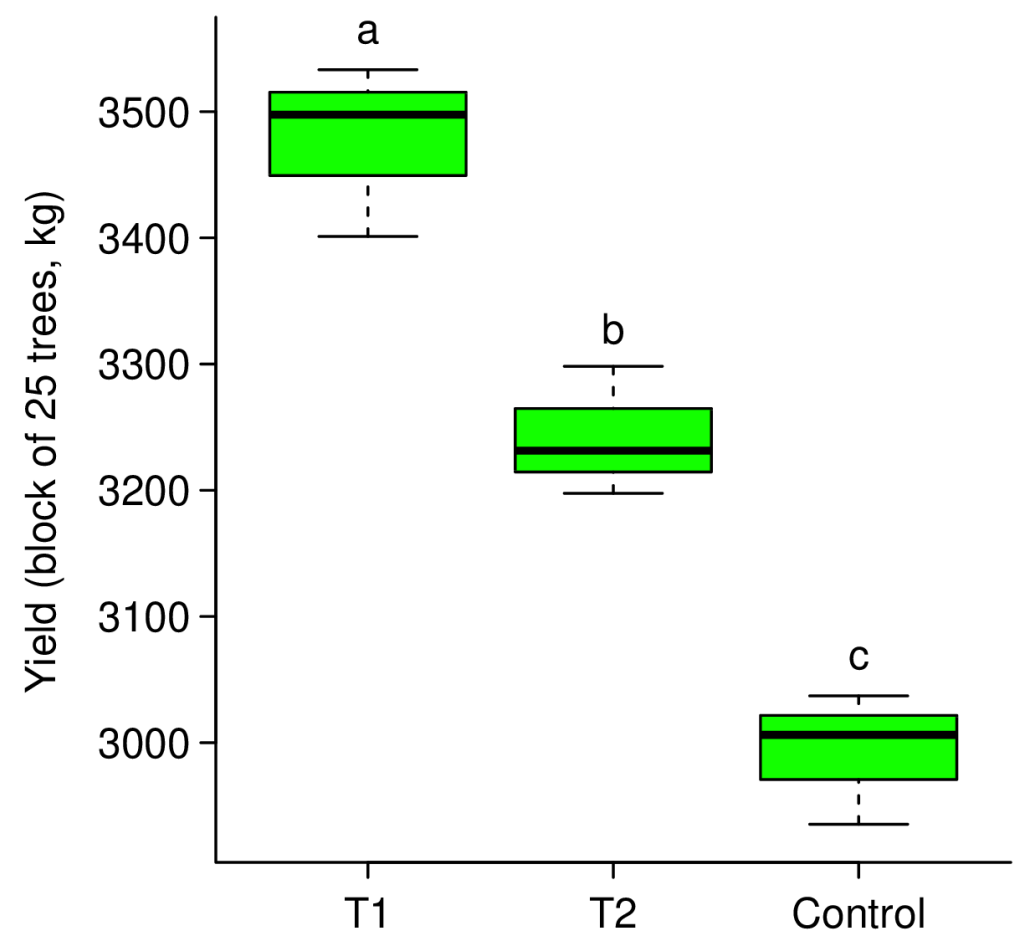

Fig. S6. Yield (kg of apples) from the treated block of 25 trees in each treatment $(\mathrm{N}=3$ orchards per treatment). The different letters above bars represent significantly different yields as estimated by a Tukey's HSD test (Table S3). 